\title{
Commercial real estate investment and economic development in the Northeast region of the United States
}

Tizita Wasihun

Follow this and additional works at: https://researchrepository.wvu.edu/etd

\section{Recommended Citation}

Wasihun, Tizita, "Commercial real estate investment and economic development in the Northeast region of the United States" (2015). Graduate Theses, Dissertations, and Problem Reports. 6918.

https://researchrepository.wvu.edu/etd/6918

This Dissertation is protected by copyright and/or related rights. It has been brought to you by the The Research Repository @ WVU with permission from the rights-holder(s). You are free to use this Dissertation in any way that is permitted by the copyright and related rights legislation that applies to your use. For other uses you must obtain permission from the rights-holder(s) directly, unless additional rights are indicated by a Creative Commons license in the record and/ or on the work itself. This Dissertation has been accepted for inclusion in WVU Graduate Theses, Dissertations, and Problem Reports collection by an authorized administrator of The Research Repository @ WVU.

For more information, please contact researchrepository@mail.wvu.edu. 


\title{
COMMERCIAL REAL ESTATE INVESTMENT
}

AND ECONOMIC DEVELOPMENT IN THE NORTHEAST REgion OF THE United STATES

\section{TIZITA WASIHUN}

Dissertation submitted to Davis College of Agriculture, NAtural Resources AND DESIGN

AT WEST VIRGINIA UNIVERSITY

IN PARTIAL FULFILMENT OF THE REQUIREMENTS FOR THE DEGREE OF DOCTOR OF PHILOSOPHY IN Agriculture AND RESOURCE ECONOMICS, CONCENTRATION IN REGIONAL AND ECONOMIC DEVELOPMENT

\author{
Tesfa Gebremedhin, Ph.D., Co-Chair \\ Peter SchaefFer, PH.D., Co-CHAIR \\ RANDALl JACKSON, PH.D. \\ SAntiago Pinto, PH.D. \\ DAle COLYer, Ph.D. \\ DEPARTMENT OF NATURAL RESOURCE ECONOMICS
}

Morgantown, West Virginia

2015

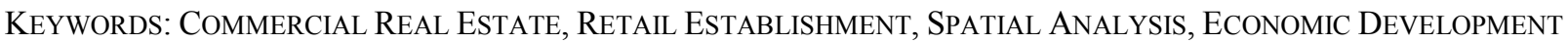
COPY RIGHT 2015 TIZITA WASIHUN 


\section{ABSTRACT \\ COMMERCIAL REAL ESTATE INVESTMENT \\ AND ECONOMIC DEVELOPMENT IN THE NORTHEAST REGION OF THE UNITED STATES TIZITA WASIHUN}

The U.S. commercial real estate (CRE, henceforth) market was pummeled during the great recession. As the economy sees gradual improvements, investment continues to forge ahead from its worst slump, with fresh opportunities as construction rebounds. The debate on the relationship between real estate investment and economic growth has a long history in the economic development literature. Frequently asked questions are, should real estate investment be part of economic development strategies? Does real estate investment have more economic benefits than other investments? Should real estate investment wait until economic growth is achieved? Does real estate investment spur economic growth or, vice versa? This study tries to revisit earlier debates by attempting to understand the economic role of CRE investments, particularly retail store establishments in the Northeast region of the United States.

This study empirically estimates the interdependent relationships between growth in retail store establishments and regional economic growth. Growth in population density, employment density and per capita income are used to represent level of regional economic growth. Theoretically, the neoclassical growth model accounts for the growth effect of CRE investment as a capital injection into the economy. The investment is also considered as a potential economic stimulant since it induces additional economic activities and adds to employment. The cumulative improvements can also have favorable spillover effect to neighboring regions.

Because retail establishments' size differences may influence the magnitude of the economic growth effect, establishment data are classified as being large or small, based on employment size. The study used both spatial and non-spatial analysis. The spatial model used spatial Durbin and spatial autoregressive models while the non-spatial model used a three stage least square (3SLS) simultaneous equation model.

The empirical results of this study on the relationship between CRE investment and economic development are an extension that incorporates the simultaneous relationship of retail establishments with other variables in the economic development of the region. The consideration of spatial dependency is also another novel contribution of the study.

The study concludes that indeed, growth in retail establishments plays a significant role in the economic growth process of the Northeast region of the United States. Although small retail establishments also contribute in the process of economic development, large retail establishments have a greater economic impact. Small retail establishments have a weak impact that is also statistically insignificant. This somewhat unexpected result is not inconsistent with casual observation and provides useful information for policy recommendations. Overall, the study provides information to policy makers on the economic role of both small and large retail establishments and socio-economic driving factors of the investment in the Northeast region of the U.S. 


\section{Dedication}

I dedicate this work to my loving parents, Alemayehu Wasihun and Mulu Hailu, for their words of encouragement, love, support and, inspiration. 


\section{ACKNOWLEDGMENTS}

A special thanks to my advisors, Dr. Tesfa Gebremedhin and Dr. Peter Schaeffer, for their countless hours of reading, commenting, guiding, encouraging, and most of all patience throughout the entire course of this dissertation. Many thanks to my dissertation committee, Dr. Santiago Pinto, Dr. Randall Jackson and Dr. Dale Colyer, for agreeing to serve as my committee, your precious time in reviewing the manuscript, and your valuable and helpful insights. Many thanks to Dr. Dennis Smith, for your willingness to act on behalf of Dr. Dale Colyer.

I would like also to acknowledge and thank the Division of Resource Management, Davis College of Agriculture, Natural Resources, and Design, for admitting me as a graduate student and offering me work as a graduate teaching/research assistant for the past years. I also like to thank the faculty, colleagues, and friends in the Division of Resource Management. I want to express my appreciation for the administrative assistance given to me by Lisa Lewis, Ellen Hartley-Smith and Melanie Jimmie. Special thanks also go to my colleagues and friends, the late Andualem Alemayehu, Dr. Xueting Zahao and Dr. Mulugeta Kahsai, for sharing expertise, providing support and encouragement, and most of all for the enjoyable experience throughout the journey.

Many thanks to the Division of Diversity, Equity and Inclusion, West Virginia University, for proving me continued financial support granted through Chancellor's Scholarship. I am especially grateful to Jennifer McIntosh, David Fryson and Sharon Mallow. There is no way to fully express my gratitude for the generosity; it surely was the best support I could have asked for.

I'm truly humbled and blessed to be surrounded by very special, supportive and caring family and friends. Finally and most importantly, I thank the Almighty God, for all the blessings, guidance, strength and care; without it, I wouldn't have made through any of this. 


\section{TABLE OF CONTENTS}

Abstract.

Dedication. ... i

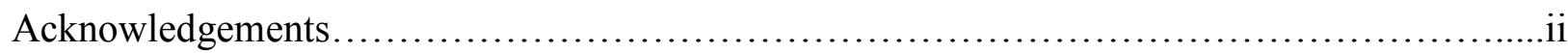

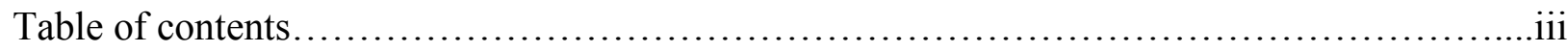

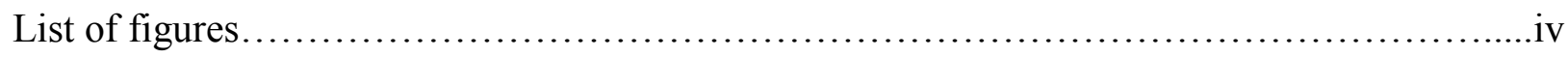

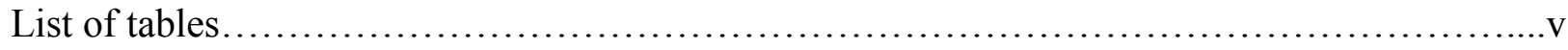

\section{CHAPTER 1: INTRODUCTION 1}

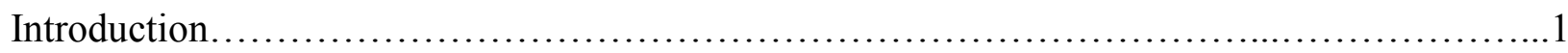

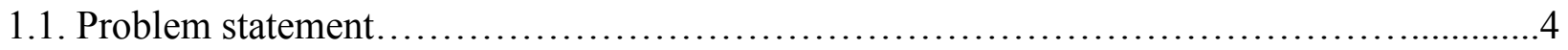

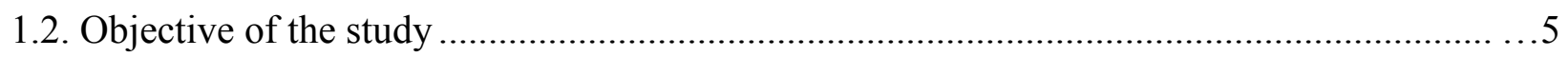

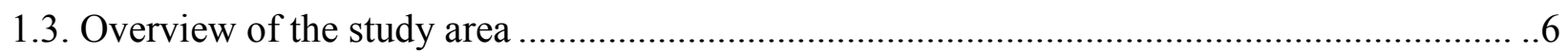

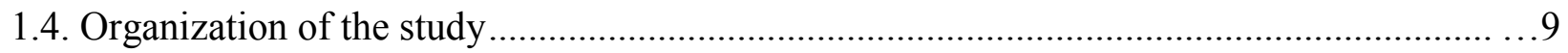

\section{CHAPTER 2: LITERATURE REVIEW 10}

2.1. Commercial Real Estate and Development ................................................. 10

2.2. Commercial Real Estate and Location......................................................................... 14

CHAPTER 3: THEORETICAL MODEL 20

3.1. Commercial Real Estate Investment and Economic Theory .......................................20

3.2. Commercial Real Estate and Growth Pole Model ..........................................................22

3.3. The Theory of Investment Location Decision ........................................................... 25

3.4. Location Decision of Firms and Cost of Production.................................27

CHAPTER 4: EMPIRICAL MODEL AND DATA DESCRIPTION 29

4.1. Non-Spatial Growth Model ........................................................29

4.2. Non-Spatial

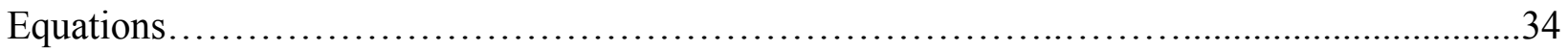

4.2.1. Population Density Growth Equation....................................... 34

4.2.2. Employment Density Growth Equation.................................35 
4.2.3. Per Capita Income Growth Equation...................................... 37

4.2.4. Commercial Real Estate Growth Equation................................38

4.3. Spatial Growth Model ......................................................40

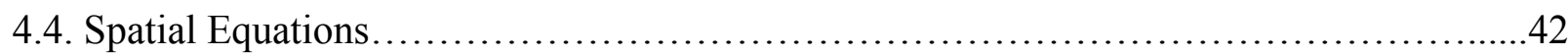

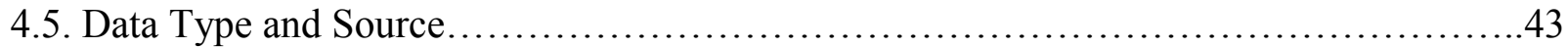

4.6. Estimation Method.........................................................45

CHAPTER 5: EMPIRICAL RESULTS AND ANALYSIS 47

5.1Size of Commercial Real Estate Investment......................................47

5.2 Non-spatial Growth Model Results...........................................48

5.3 Spatial Model Results.......................................................58

CHAPTER 6: SUMMARY AND CONCLUSION 68

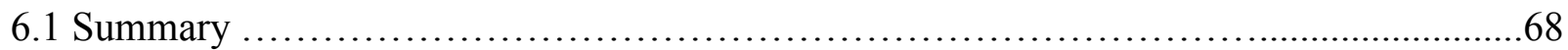

6.1 .1 Non-spatial Models..................................................68

6.1.2 Spatial Models.................................................... 72

6.2 Conclusions and Policy Recommendation...................................... 75

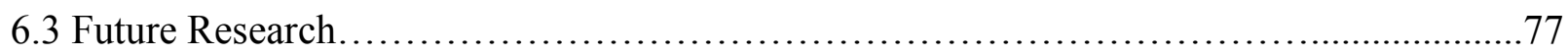

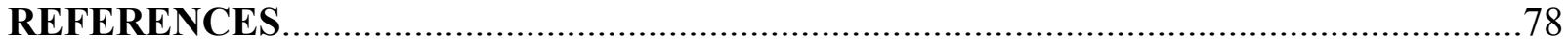

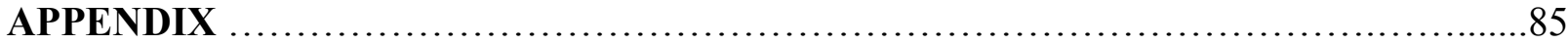




\section{LIST OF FIGURES}

Figure 1.3.1. Metro and Non-Metro Counties in the Northeast Region .......................7

Figure 1.3.2.Retail Establishment Intensity by County in the Northeast Region ............... 8

Figure 1.3.3. Retail Employment by County in the Northeast Region.....................................9 


\section{LIST OF TABLES}

Table 3.2.1: Types of Data Affecting Commercial Real Estate Investment......................16

Table 4.5: Definition of Variables and Sources ........................................45

Table 4.6. Descriptive Statistics for the Northeast Counties 2000-2010.....................46

Table 5.2.1. Three Stage Least Square Results of Growth in Population Density.................49

Table 5.2.2. Three Stage Least Square Results of Growth in Employment.....................52

Table 5.2.3 Three Stage Least Square Results of Growth in Per Capita Income.................54

Table 5.2.4 Three Stage Least Square Results of Growth in Commercial Real Estate

Investment...................................................................5 57

Table 5.3. Estimated Value of Spatial Dependence Statistic, RHO ...........................60

Table 5.3.1 SAR Results of Growth in Population Density ..............................................61

Table 5.3.1 SDM Result of Growth in Per Capita Income.................................................65 


\section{CHAPTER 1. INTRODUCTION}

\section{INTRODUCTION}

Commercial investments constitute a large segment of the real estate market and are both an engine for, as well as an indicator of, economic development. For the purpose of this study, commercial real estate is defined as buildings owned to generate income and profit through rent and property appreciation. Example includes offices, warehouses and retail/wholesale stores.

The direct impact of commercial real estate (CRE, henceforth) investment on the construction industry is particularly significant. It includes not only new construction, but also investments in renovation and major maintenance projects. According to the U.S. Bureau of Economic Analysis (BEA) in 2007, new commercial construction contributed $\$ 549$ billion to U.S. Gross Domestic Product (GDP), or 4.1 percent of the total. It decreased to $\$ 376$ billion in 2010 due to the recession, but rebounded to $\$ 436$ billion in 2013, when it accounted for 2.7 percent of the total U.S. GDP. According to the National Association for Industrial and Office Parks (2012), CRE construction in 2011, supported approximately 2 million jobs. The indirect impact of CRE investment includes additional induced investments - such as businesses that tend to follow large investments, and associated increased employment opportunities. In addition, governments derive new revenues from property, sales, and other taxes, but net new revenues are smaller because of expenditures serving newly developed places and possible tax revenue losses because of businesses that suffer from new competition.

CRE investment is a sector comprising different industries. Investigating the aggregate role of CRE investments as one sector is, therefore, inadvisable because each set of industries has a different set of drivers influencing its performance. The success of one type of property doesn't imply that a different type of property will also succeed. Therefore, this study will examine only 
one segment of CRE investments_retail establishments ${ }^{1}$ - to estimate potential relationships between this sector and economic development.

According to the U.S. Census Bureau's (USCB) Statistical Abstract (2012), the retail service industry has more than one million stores in the U.S. and accounts for more than four trillion dollars in sale revenue (about 6 percent of U.S. GDP). The industry employed 15 million workers in 2012, which is about one out of every 10 U.S. workers. The industry is also projected to show the largest real output growth among all industries by 2020 and the second largest employment growth (Bureau of Labor Statistics (BLS), 2012).

Traditionally, the retail sector is considered as a "non- basic industry"; meaning that the sector recycles money within an area without bringing new money from the outside. This industry is assumed to have little tangible economic impact because it depends largely on local customer and business (Ducatel and Blomley, 1990; Lowe and Crewe, 1991). The local economy is assumed strongest when it relies on industries that primarily depend on external market/income, "basic industry".

Despite the previously neglected role of retail establishments as a basic-industry, today's regional and development professionals recognize the dual roles of the retail sector, as a basic as well as non-basic industry. As a basic industry, the retail sector is recognized to contribute to the economy by deriving demand flows from outlying customers. The recent boom in online retail is a major contributing factor for businesses to have a better opportunity to reach beyond local borders. As a result, the geographic location of stores has become less of a barrier to customers and businesses. The fact that the shopping habits of customers have also become flexible, in terms

\footnotetext{
1 "The sector comprises establishments engaged in retailing merchandise, generally without transformation, and rendering services incidental to the sale of merchandise" (USCB, 2007).

http://www.census.gov/eos/www/naics/2007NAICS/2007 Definition File.pdf . Accessed, January 30,2015
} 
of traveling longer distance than they previously did, also made the geographic location of stores to relatively have less effect on the location of customers. Apart from this, the strategic location of some stores can be a major source of external income. An example of this is Tamarack, a major tourist attraction retail center in Berkley, West Virginia, located on I-77, exit 45. A survey done by Price et al. (2008) indicated that about 75 percent of those who stopped at Tamarack were nonWest Virginia residents. The retail sector indirectly also improves perceived quality of life, and reduces other stakeholders' perceived investment risks in an area. This leads to the development and attraction of new businesses, bringing additional income to a region. As a non-basic industry, apart from serving the local market, the retail sector also plays a major role as a "leakage preventer", by reducing the expenditures that would otherwise "leak" out of the region. (Williams, 1997; Gibson et al., 2003).

There is a growing number of studies examining the economic contributions of CRE investments, in general, and retail establishments, in particular. Some of the research has shown that retail establishments contribute to economic development by attracting new businesses to the region that offer goods and services and provide employment opportunities (Ling and Naranjo, 1997; Vias, 2004; Nowark, 1997). This enhances the multiplier effect of household expenditures and also creates backward linkages to suppliers (Ling and Naranjo, 1997; Hongyu et al., 2002). Some researchers also have examined the role of CRE investments in enhancing the physical environment and its influence on residential location decisions, and related positive impact on housing value. (Seidman, 2006; Colwell et al., 1985; Porter, 1997). CRE investment has also been found to positively contribute to residents' self-perception of their neighborhood and reduce stakeholders' perceived investment risks (West and Orr, 2003).This also attracts new residents and businesses to an area. 


\subsection{Problem Statement}

Commercial real estate investment, in general, and investment into retail establishments, in particular, has been seen as fostering development beyond the initial investment. Such investments include construction, renovation, and major maintenance; they are characterized by very large expenditures and significant job generation. Retail investments also tend to enhance local and regional spending, thus increasing the multiplier effect of increased spending. Additionally, they may attract complementary businesses (Pittman and Culp, 1995; Gibson et al., 2003).

Despite the positive contributions of retail investments to an area, the investment decisions and their specific geographic placements tends to be affected by the already existing economic, infrastructure, and demographic characteristics of an area. (Nair, 2011; Wincott and Mueller, 1995; Thilmany et al., 2005; Lieser and Groh, 2011; Jackson, 2001; Alwitt and Donley, 1997; Boon, 2005; Colavolpe, 2010; Malizia, 1991; Fickes, 2007).These characteristics have been major criteria for most retail business location decisions. Areas that have prior degree of urbanization in terms of population density, per capita income, industry mix, public transportation etc. tend to be attractive for investors and subsequently, become economically advantageous compared less economically privileged areas. In line with Miller and Weber, (2014) analysis result, majority of rural U.S. counties show persistently slow population growth, high unemployment rate, growing poverty rates, and increased gap in per capita income compared to their urban counter parts. These characteristics of rural communities present challenges to attract new potential investors and retain existing businesses that are able to stimulate job opportunities and income to those areas. This challenge also pertains to CRE investors and retail businesses across the region. To understand the economic contribution of retail establishments in the regional growth process and identify the 
socio-economic factors that affect the growth of the investment, this study first, differentiate retail establishments from other forms of commercial and non-commercial real estate investments and, explores the potential economic contribution of the sector. Second, the paper examines how socioeconomic and demographic disparities within a region affect the growth of the investment to provide crucial information for decision makers and draw effective policy mechanisms to attract businesses, stimulate job opportunities and income in the region.

This study will investigate and analyze the interdependent relationships between such as population growth, employment, per capita income, and retail business growth. This study differs from most previous studies by including the spatial distribution of investment and their possible spillover effects to neighboring regions. The model assumes that the number of retail establishments in a county depends not only on its own economy, but also on socio-economic conditions and retail establishments in neighboring counties as a potential source of demand or as competitors. The inclusion of space model also addresses statistical problems of bias or inefficiency of the estimators that may arise because of spillover effects (Anselin, 1988). Understanding the role in the economic development process played by retail establishments provides information to stakeholders, including local governments that have to decide on policy direction and justify expenditures for implementing policies and programs.

\subsection{OBJECTIVES}

The overall objective of this study is to provide policy makers with information on the relationship between commercial real estate investments particularly, retail establishments, and economic development in the Northeast region. The specific objectives are to: 
1. Develop a database of socio-demographic and economic variables for the Northeast region

2. Identify and estimate the impact of commercial real estate investment, particularly in retail establishments, on the economic development of the Northeast region.

3. Identify the spatial distribution and spillover effects of commercial real estate investment, particularly of retail establishments, in the economic development process.

4. Based on the research findings, draw policy implications for economic development in the region.

\subsection{Overview of the Study Area}

The study area is the Northeast region of the United States. It consists of 299 counties in the states of Connecticut, Delaware, Maine, Maryland, Massachusetts, New Hampshire, New Jersey, New York, Pennsylvania, Rohde Island, Vermont, and West Virginia. This region is the oldest region of the United States and very diverse. It includes the nation's largest city, New York, and its smallest state, Rhode Island. State populations also vary greatly, from approximately 625,000 in Vermont to 19 million in New York (U.S. Census, 2010). The region has a long history and rich culture and offers a diverse set of economic opportunities. According to the U.S Census 2010 population data, the region's population was 64 million, which is equal to 20.5 percent of the total U.S. population. The average population change from 2000 to 2010 was 3.8 percent and ranged from 0.2 percent in Rhode Island to 14 percent in Delaware. This wide range reflects differences in job opportunities, economic and business conditions, education, infrastructure, and services. According to the USDA-ERS county metro and non-metro typology $(2004)^{2}, 55$ percent

\footnotetext{
${ }^{2}$ Metro counties are counties that contain urbanized areas containing at least 50,000 people, or are outlying counties that are economically linked to urban counties through significant commuting workers, and classified as non-metro counties, otherwise. (Office of Management and Budget)
} 
of the counties in the region are classified as metro; they accounted for 85 percent of the total population in 2010. Metro and non-metro counties of the region are shown in figure 1.3.1, below.

Both metro and non-metro counties showed about the same population growth rate from 2000 to 2010 . The average annual per capita personal income of metro counties exceeded non metro counties by an average of $\$ 7,500$ in 2010 .

\section{Fig 1.3.1. Metro and Non Metro Counties in the Northeast Region}

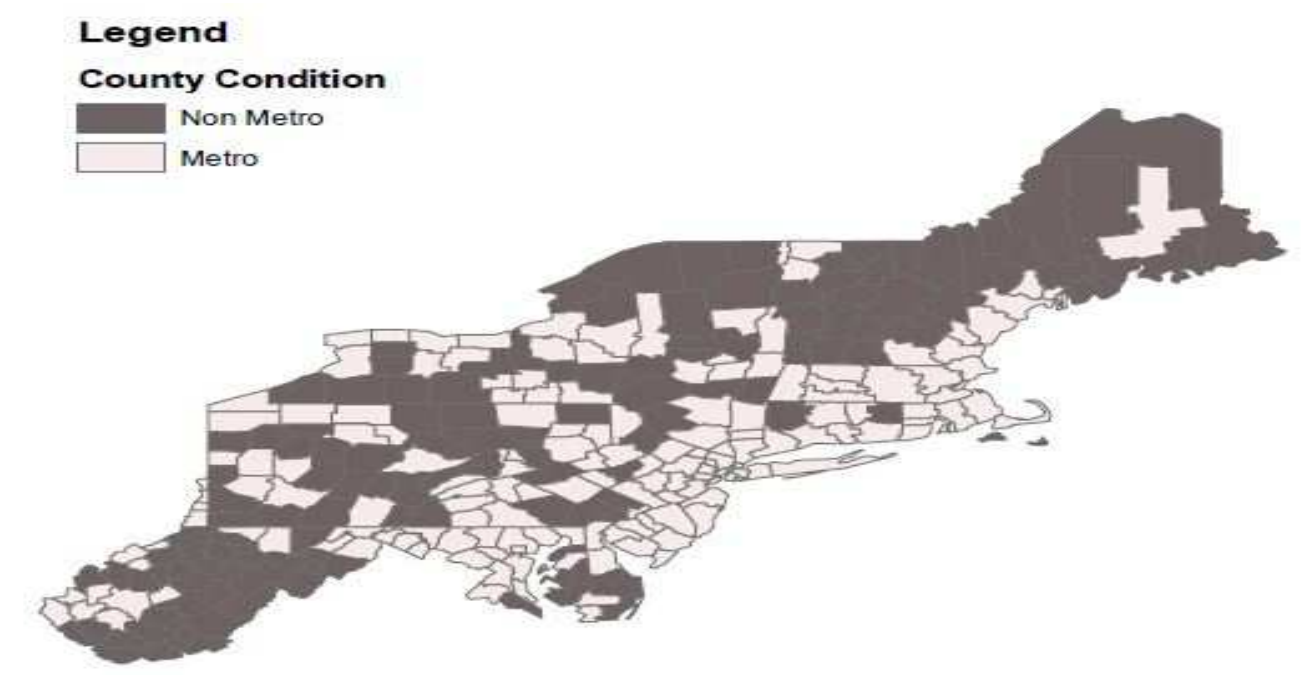

Source of date; USDA-ERS county metro and non-metro typology, 2004

According to BEA data, total employment in the region increased by 5 percent between the year 2000 and 2010, which is about the same as the national average. Forty-one percent of the counties increased at a rate above the regional average, and 31 percent experienced an employment decline. Average per capita income in the region increased by 39 percent between the year 2000 and 2010. Fifty-three percent of the counties experienced growth above the 31 percent national average per capita growth while, only 16 percent of the counties showed per capita income growth below the national growth rate.

According to the Unites States Business Statistics (USBS) database on the number of retail establishments for the year 2000, 17 percent of the counties had retail establishment intensity 
(population per retail establishments) of less than 200; meaning that a single retail establishment served less than 200 people. The top three counties with the lowest population per retail establishment were Nantucket and Dukes counties in Massachusetts and Worcester, Maryland. Approximately 20 percent of counties had a retail establishment intensity above 300 (a single retail establishment served more than 300 people). The bottom three counties with the highest population per retail establishment were Lincoln, Taylor, and Doddridge counties in West Virginia. Retail establishment intensity within counties of the Northeast region is shown in figure 1.3.2, below.

\section{Fig 1.3.2 Retail Establishment Intensity by County in the Northeast Region}

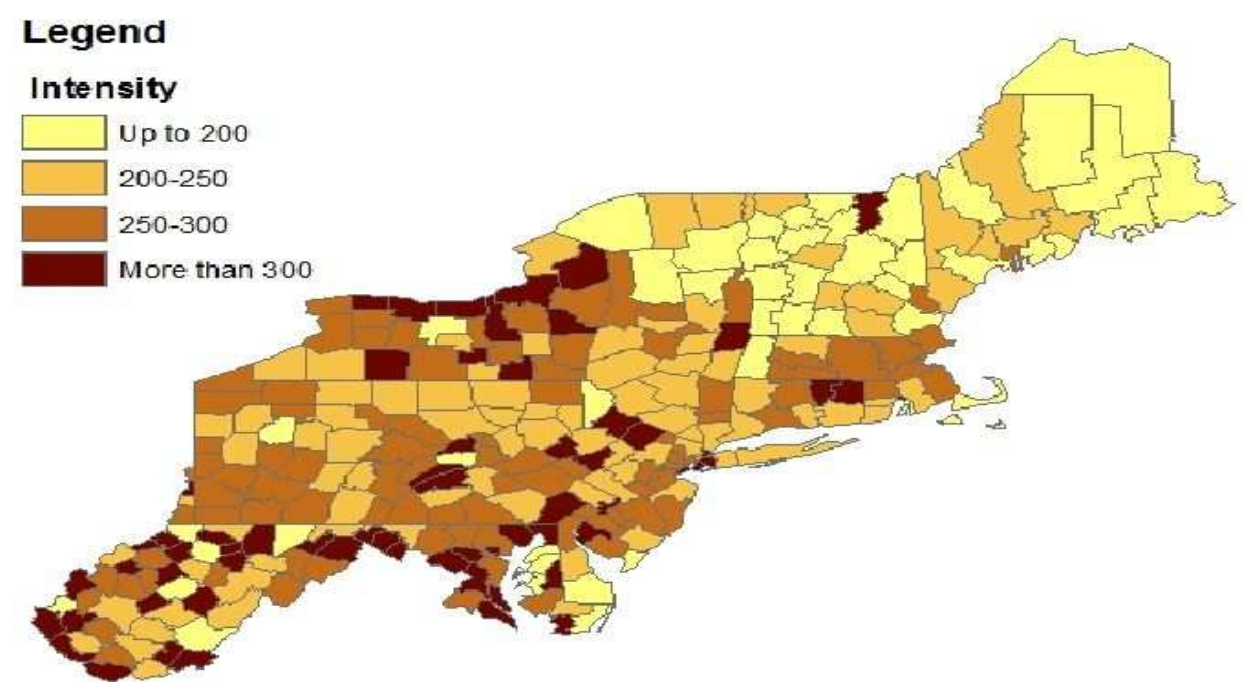

Source of data; U.S. Census Bureau's Statistics of U.S. Businesses (SUSB) and Business Pattern Statistics, 2010

Although total employment in the retail industry declined by 2 percent from 2001 to 2010 , it contributed approximately 10 percent of total employment in 2010. According to the $2001 \mathrm{BEA}$ data, 24 percent of the counties in the region had fewer than 2,000 employees in retail whereas approximately 13 percent of counties had more than 30,000 employees; New York County in New York State with close to 140,000 employees had the most. Figure 1.3.3 below shows the number of retail employees within counties of Northeast region. 


\section{Legend}

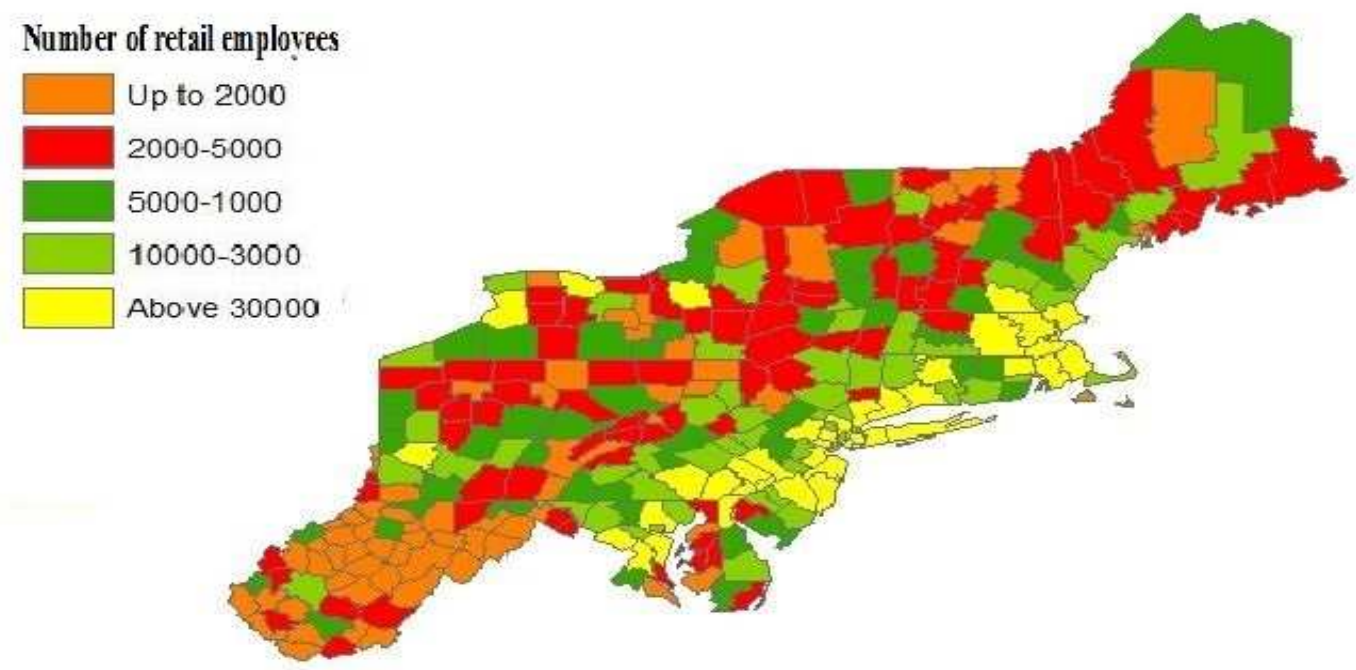

Source of data; U.S. Department of Commerce, Bureau of Economic Analysis, 2010

\subsection{ORganization OF THE STUDY}

This study is comprised of six chapters. Chapter 2 provides a review of the literature explaining the relationship between CRE and development, and factors affecting location decision of CRE investors. Chapter 3 presents the theoretical background for modeling CRE investment and economic development. Further, chapter 4 introduces the empirical models and the types and sources of data used in the empirical analysis. Chapter 5 contains the estimation results and interprets them, particularly with respect to policy implications. Finally, Chapter 6 summarizes the results, conclusions, and policy recommendations and suggests directions for possible future research. 


\section{Chapter 2. Literature Review}

\subsection{Commercial Real Estate and Development}

The idea of investing more for capital accumulation and then growth was motivated by Harrod (1939) and Domar (1946). Their exogenous growth model gives an insight on how investment in general leads to economic growth through increased savings and productivity. The model has been extended by Solow (1956) when the contribution of technology came in to attention in the productivity and growth process. Romer (1986) also further extended the model by pointing out the endogeneity nature of technological progress to acquire increasing returns and capital formation. The contributions of real estate investments to GDP have been identified by many researchers. Green (1997) used time series data and Granger's causal inference method to analyze the relationship between GDP, housing, and non-housing investment at the national level. His results indicated that housing investment contributes significantly to GDP, but not vice versa, whereas non-housing investment doesn't boost GDP but rather vice versa. This finding highlights the potential role of real estate investment in stimulating GDP. Green concluded that housing investments lead the business cycle while other types of investments lag it. The result also suggests that policies designed to drive away capital from housing could generate severe dislocation.

Coulson and Kim (2000) argued that the Granger-causal inference used by Green (1997) may not reveal the true causal aggregate forces that influence GDP because this inference ignores the components of GDP other than housing in determining the effect of housing on GDP. To address this issue, they used a multivariate autoregressive model to understand the influence of housing and non-housing investment on GDP and its components. Their result is consistent with that of Green (1997), which showed a more pronounced effect of housing investment on GDP compared to non-housing investments. 
The analysis of China's data revealed similar evidence to that of U.S.-based studies. Subsequent to the housing reform of 1998 and related encouragements from the Chinese government in terms of relaxed standards for construction permits and easy credit access, China's real estate investment accelerated, especially its commercial housing sector. To understand the implications of this accelerated investment in China's economy, Hongyu et al. (2002) analyzed the long- and short-term effects of housing and non-housing investments. Their results indicate a stronger short-term effect of housing investment compared to non-housing investments. They also noted that housing investments have a strong long-term economic effect, while economic growth has a long-term effect on non-housing as well as housing investments. Their results suggest the important role of housing for short-term economic fluctuations and long-term economic growth.

Brito and Pereira (2002) used an endogenous growth model composed of three types of capital: housing capital, non-housing capital (such as machinery and transportation equipment), and human capital. Residential and commercial real estates were included in this model, where residential real estate plays the dual roles of being an investment and consumption good for households, and commercial real estate plays as an input into the production function with both physical and human capital. A key assumption in the model was that housing and other assets are not perfect substitutes. This assumption ensured the growth rate depended on the relative price of the different capitals. The result supported a long-term positive growth rate of housing and nonhousing-related production parameters such as construction, manufacturing, and human capital.

CRE investment comprises a large segment of the housing industry. Over the past decades, this investment has attracted the attentions of scholars because of its economic contribution to residents and effect on the built environment. It accounts for 6 percent the total U.S. GDP 
(Ambrose and Lusht, 2008) and has become a core investment asset as it has a relatively stable income stream (Ruff, 2007).

According to the analysis by Florence et al. (2010), which was based on 2009 U.S. data, CRE investment accounted for over 100 billion square feet of space, or 328 square feet per person. Of this 100 billion square footage, 24 billion is allocated for industrial space, nearly 23 billion for multifamily space, over 17 billion for retail space, and over 12 billion for office space.

The total transaction volume of CRE investment revenue has shown growth over the years. The turnover was $\$ 65$ billion in 2001, $\$ 160$ billion in 2004, and $\$ 300$ billion in 2006 (Ambrose and Lusht, 2008).This represents growth of 350 percent over the period of 6 years. A comparative analysis by Ruff (2007) on the return of U.S. CRE versus stocks and bonds, using data from 19872006 found that CRE's 9.4 percent return was lower than stocks (11.5 percent), but above that of bonds ( 7.3 percent).

CRE investment also plays a positive economic role through assisting the progress of different economic activities. For example, investment in a shopping center may lead to the success of retail, wholesale, and other personal service industries, while office investment attracts a range of activities in professional, financial, and others. Porter $(1995,1997)$ noted how commercial places play a role in enhancing physical environment, employment, tax revenue, and further investment in an area. These positive attributes influence the location decision of households, and the co-existence of residential housing and business centers helps to keep a viable community and sustained economic development. Pittman and Culp (1995) argued that in order for commercial establishments to count as contributors in economic development, it is important that they draw expenditure from outside areas and eliminate or reduce expenditure leakage by local consumers. Gibson et al.'s (2003) research also supported the idea that the potential community welfare role 
of business establishments is realized only when it is possible to reduce trade leakage and improve the quality of life of the residents.

West and Orr (2003) highlighted the intangible benefits of commercial real estate establishment by analyzing the perceptual opinions of residents about Providence Place Mall in Rhode Island. Their survey analysis showed that residents believed downtown malls were the engines of economic development and were helpful in making residents feel positive about their neighborhood. The survey results also showed that the mall encouraged shoppers to visit other stores and restaurants in the downtown area and induced economic spillover to the surrounding area.

Colwell et al. (1985) found both positive and negative effects of small neighborhood shopping centers on the surrounding property values in Urbana, Illinois. They used a hedonic regression model to explain the variations in property values of 43 single-family homes and condominiums before and after the announcement of a proposed shopping center. The positive effect on the property values were observed in properties beyond 1,500 feet from the intended shopping center, while the diseconomy was on those properties closer than 1,500 feet. The result indicates the possible negative externalities that may arise due to shopping center proximity. They suggested that the negative externalities likely can be balanced by considering optimal spatial frequency in the establishment of business centers.

Ding and Knaap (2002) focused on the relationship of housing value with housing investment and business establishments. Their results indicated an unambiguous positive relationship between housing value and new housing investment, but a negative relationship with new business establishments. They thought the negative relationship with new business establishments could be related to the zip-code level data they used and that proximity to business 
establishments may have caused the negative externalities. Regardless, they indicated the need to consider ways to minimize negative externalities in construction plans.

Chapple and Jacobus (2009) studied the relationship between the growth of chain stores and the economic status of neighborhoods in San Francisco. The analysis indicated a positive relationship of chain stores with "middle-class income becoming" neighborhoods as oppose to economically "stratifying" or "gentrifying" areas. The "middle-income becoming" neighborhood areas on average showed a disproportionate share of retail establishments compared to the other groups. The results indicated that an increase in the retail sector is closely related to an increase in middle-income residents (rather than gentrification or other forms of neighborhood changes).

\subsection{Commercial ReAl Estate InVESTMEnT AND Location Attributes}

Apart from the possible economic contributions of CRE investment to a region, an investment location decision by the developers and the scope of investments depend on the economic activities and demographic characteristics of regions. Considering the capital-intensive nature of the investment, Nair (2011) emphasized the importance of establishing a sound investment location and knowhow of the demand and supply dynamics of the market prior to making an investment. Some of the location and demand factors he addressed were infrastructural development, the job market, population growth, and amenities. Furthermore, he stressed the importance of analyzing income-producing asset features such as break-up cash flow, vacancy factors, maintenance costs, and capital appreciation potential in the decision process of potential investors.

According to a commercial property-specific demand factor analysis by Wincott and Mueller (1995), beside the factors such as population, employment, income, and disposable income, and factors such as total retail sales volume per retail center, total retail sales volume per 
household, retail sale factor (retail sale as a percentage of disposable income), and sales per square foot were some of the identified retail-store demand drivers.

Malizia (1991) argues for the importance of economic development variables instead of economic growth variables in the long-term productivity and innovative potential of an investment area for commercial real estate. Some of the demand factors he pointed out are education attainment level, industry mix, and employment diversity. Colavolpe (2010) explained that evaluating criteria such as a sales volume forecast, quality and quantity of competitive retailers, demographics of an area, and target customers, are potential success factors in a real estate site selection process. Lieser and Groh (2011) also provided evidence that factors like rapid urbanization, economic growth, and compelling demographics attract real estate investments. Jackson (2001) argued that the demand in the retail property market is largely a function of demand from end-customers. This demand can be explained by the level of expenditure and measured by the level of disposable income. He further explained that when exact data is not available, proxy variables such as income and percentage of working population can be used to capture the consumers' expenditure potential in an area.

Boon (2005) classified different demand variables in commercial real estate market analysis based on four categories: economic, politics, demographic, and real estate information as shown in Table 3.2.1. 
TABLE 3.2.1.TYPES OF DATA AFFECTING COMMERCIAL REAL ESTATE INVESTMENT

\begin{tabular}{lll}
\hline No & Category & Variables \\
\hline $\mathbf{1}$ & Economic & GDP, Inflation, Retail sales index, FDI, Unemployment rate, Interest rate, \\
& & Exchange rate, Forecast of economic indicators, Sovereign credit risks \\
\hline $\mathbf{2}$ & Politics & political risks \\
\hline $\mathbf{3}$ & Demography & Population size, Per capita income, Household size, Household income, \\
& & Living space, Demographic forecasts \\
\hline $\mathbf{4}$ & Real estate & Existing stock, Historical and forecast of supply, Demand, Vacancy, \\
& information & Rental, Yields and total returns, List of sales transactions and buyers' \\
& & profile
\end{tabular}

Adopted from Boon (2005)

Beyond the general demographic and economic factors, Fickes (2007) explained the role of psychographics evaluation in the site selection process. These included the attitude, value, and lifestyle of target consumers in new store construction.

Given the central place theory premises of the possible positive relationship between population density and number and type of establishments in a community, Thilmany et al. (2005) hypothesized that the population threshold of communities may give an idea about the type of retail stores one can expect to find. To investigate the relationship, they focused on nonmetropolitan communities in the Intermountain West and included 183 rural communities within 129 counties. Their results indicated a positive and significant effect of population level in the number of establishments. Moreover, adjacency to metropolitan areas also had a positive effect, particularly on the number of establishments in the merchandise and apparel industries. This result suggests that the number of establishments in neighboring areas depends highly on local demand conditions population. They also found a positive relationship between per capita income of an 
area and number of retail stores, implying that the income of the population plays a role in sustaining establishments.

Mushinski and Weiler (2002) used a simultaneous equation model to evaluate the interdependencies between the number of establishments in an area and the numbers of establishments and population in a neighborhood area. Their data included 183 rural communities within 129 counties of the Intermountain West Region. Their result indicates that the number of establishments, particularly in neighboring areas, has a negative significant relationship with the number of establishments in that area. The combined impact of population, directly and indirectly through number of establishments is generally negative in indicating that the population level in neighborhood areas draws away potential demand. They concluded that the number of establishments in neighboring areas negatively affects the number of establishments that could present in an area, thus implying a possible spatial competition in retail industries.

Wensley and Stabler (1998) used Harris and Shonkwiler's count data techniques to study the extent to which spatial competition can be measured by how urban proximity interacts with population to provide the threshold demand for a particular business. The study used 590 Saskatchewan communities. Their findings indicated that larger and more remote areas have a lower demand threshold that resulted in a higher frequency of establishments relative to areas adjacent to urban areas. Their argument is that geographic isolation transportation cost make the relative cost of rural establishments more competitive relative to their urban counterparts. Handerson et al. (2000) used similar count data techniques as Wensley and Stabler (1998) to illustrate the tradeoff between population and urban proximity in specialized hospital services in Texas. In contrary to Wensley and Stabler (1998), results by Handerson et al. (2000) indicate that given there is an agglomeration economy, urban proximate markets have lower demand thresholds 
and higher frequencies. This implies that the presence of economies of scale overshadow the benefits of geographic isolation. These two contradicting results suggest that geographic interdependencies and threshold demand for retail establishments may vary by sector.

Using a two-dimensional spatial competition model, Konish (2005) tried to show the tradeoff between market size and the price-cutting effect of store concentration. His model estimation indicated that the market size effect is much stronger for small-scale store concentrations, but as the concentration increases, the price-cutting effect ultimately dominates the market-size effect.

Alwitt and Donley (1997) investigate the hypothesis that poor neighborhoods are disadvantaged in having access to retail establishments. They used poor and non-poor zip codes of Chicago for their analysis and controlled purchasing power. Their result did not find a statistically significant difference in the total number of retail establishments, but did find a significant difference in retail establishment size between the two different zip codes. This suggests the importance of capturing establishment size in analyzing the relationship between demographic and socioeconomic variables of an area and the number of establishments.

Bowes (2007) used a two-stage simultaneous equation model to investigate the hypothesis that crime in an area discourages retail development. His data observed 206 census tracts of metropolitan areas in Atlanta, Georgia, from 1991 to 1994. His results indicate that total crime negatively affected retail development. He further classified the crime data into property and violent crimes to see the effect of each variable. His results suggest that violent crime has a more pronounced effect in deterring retail development.

Local governments offer different tax incentives in an attempt to attract business. Schneider (1985) investigated the effect of fiscal differences on firms' locations. He used a sample of 800 
suburbs in 44 SMSAs (among 100 largest SMSAs) and modeled three separate equations with growth in the number of retail, wholesale, and manufacturing between 1972 and 1977 . He also included other explanatory variables to account for the market condition of individual SMSAs. The results showed a strong property tax base attracted all types of business establishments and higher tax rates repelled them. Local government expenditures, reliance on government transfer payments, and debit ratio variables did not show a significant relationship with growth in business establishments. Compared to manufacturing, these results also indicated that retail establishments are more sensitive to other market variables. Retail growth showed a strong and positive relationship with growth in population and median income mostly in White population areas.

Hanson and Rohlin (2011) used the Empowered Zone (EZ) program, which is a set of incentives offered to establishments in specific geographic areas within cities. To analyze the effect of tax incentives on the locations of new business establishments, the researchers compared a group of areas that applied for the program and qualified with a group of areas that applied but did not receive the benefit to counterfactual the effect of the benefit. Their analysis suggests a positive and significant effect of the EZ tax incentive program in attracting new establishments. The positive effect is particularly large in the retail and service sectors. 


\section{Chapter 3. TheORETICAL MODEL}

\subsection{COMMERCIAL REAL ESTATE INVESTMENT AND ECONOMIC THEORY}

The economic impact of CRE investment in a region may vary temporally as the impacts generated in the construction process are different from post-construction impacts. This is due to the different economic stimuli in each period. The role of CRE investment in the development process of a region can be supported by a hybrid view of theories. The construction process, being a capital-intensive investment, contributes to an economy through expenditure and different job opportunities. This contribution can be explained by the Solow growth model (1956). The postconstruction economic benefits of CRE investments that can be achieved through indirect stimulation of other businesses and economic activities in a region can be explained by the initial growth pole theory perspective of Perroux (1950). A brief explanation of the Solow growth model and growth pole theory follows below.

The neo-classical Solow growth model (1956), in general, shows how the interaction of saving, labor, and technological progress affect the level of output and emphasizes the role of capital formation for growth. The model is an improvement over the Harrod-Domar model in terms of the assumed substitutability of factors of production and contribution of technology in productivity and growth process. The model assumes the production of a single good with constant technology, fully employed factors of production, and constant labor growth in a closed economy. With these assumptions, the produced good in the model is considered as real income for individuals who consume some part and save the rest. Saving is assumed to equal investment since this is a closed economy and the model hypothesizes, given technological progress, saving ratio leads to higher per capita production and real income. 
The exogenously determined technological progress assumed by Solow (1956) has been challenged by Romer (1986) who extended the model by pointing out the endogenous nature of technological progress. He argued that new knowledge and technology are produced consciously to acquire increasing returns that neutralize the assumed diminishing marginal productivity of capital in the Solow model.

The growth pole theory (Perroux, 1950) can be applied to explain the post-construction economic benefits of CRE investments in terms of attracting other residents and businesses to a region. The first perspective of growth pole theory refers the attraction of investments and the concentration of economic activity in poles from where the stimulation of economic activity is expected to be generated and diffused into the surrounding region. The "growth pole" is initially described as a dominant stimulant firm that induces interactions between input and output. Perroux defined space as a plan or a set of interactions between "the firm and, on one hand, the suppliers of input (raw materials, labor, power, capital) and, on the other hand, the buyers of output (both intermediate and final)" (Perroux, 1950: 95). This economic space is an abstract space characterized by potential initiatives of the head firm that induce an increase in output, employment, new innovations, and expansion of related and new business in an area. The extent of influence can be measured by the intensity of inter-sectorial exchanges and networks. Therefore, this growth pole is not just a successful firm; instead, economic activities within it also influence other activities in the surrounding areas. In this regard, growth pole theory can explain the possible post-construction economic effect of $\mathrm{CRE}$ investments in a region through indirect stimulation of other businesses and economic activities that are believed to generate job and income in a region.

Perroux's first perspective of a growth pole, the abstract economic space by a stimulant firm, is extendable to the regeneration of specific geographic centers such as a city and region 
(Hansen, 1967; Parr, 1973). The application of this concept has also dominated regional economic planning in the urban city commercialization, downtown, and metropolitan center regeneration process with an assumption that this center-specific progress will have favorable spillover effects to the surrounding "zone of influence." This specific location-based development is also supported by the agglomeration force behind the "new economic geography" and geographic concentration, leading to increased return to scale (Krugman, 1999), industrial clustering and specialization (Krugman and Venables, 1996), and the role of urbanization as a fundamental element of national and international commercial relations (Fujita et al., 1999).

\subsection{COMMERCIAL REAL ESTATE INVESTMENT AND THE GROWTH POLE MODEL}

Rajendra et al. (2002) extended an evolutionary biological growth model developed by Kohonen (1997) to explain the growth pole dynamics in regional development. The applicability of their evolutionary approach to a growth center is based on the assumption that these centers undergo changes, variations, and adaptations in the growth process. Their model explains the process of economic development by CRE investments in a region. At the initial stage of the growth process, the model explicates how the decision to invest in an area depends on location factors from which developers expect to get utility. Once an investor decides to invest in an area, the model also explains the process of how one investment in an area attracts more investment and economic activities that lead to more growth in a spatio-temporal course. Furthermore, the concept of carrying capacity in their evolutionary development processes also explains the possible spread and backwash effects of development-related indicators to neighboring regions.

The model, assumptions, and key features in the dynamic process are summarized by Rajendra et al. (2002). The major assumption of their model is that if the expectation or preference of an agent (potential developer/firm) matches the landscape (investment location) attributes, then 
the developer will adapt to and modify the landscape/location to make it more suitable. Under this assumption, the interaction between the agent and landscape improves the attributes of the location (goods and services). These improvements create new niches for other agents and this dynamic and complex agent-dominated landscape attracts even more agents. By repeating the process in time and space, the matching process leads to an emergence of growth centers.

Features involved in the evolutionary growth center model are (1) agent expectation/preference; (2) landscape attributes. The matching between the agent's expectations and landscape attributes, "goodness of fit," measures the utility that an agent gets by locating at a certain location; (3) interactions between the agent and location; (4) change in the agent's/developer's expectations and landscape attributes that create a new agent-dominated landscape with improved attributes; (5) the combined agent-landscape-improved attributes serve as a new attractor for new potential agents, who then become part of the existing landscape; and (6) when the carrying capacity of the landscape reaches its limit, the agents/developers begin to search for other landscapes (repeat steps 1 through 5).

The model:

1. Each parcel of land, $i=1,2,3 \ldots . . n$ is identified as a set of attributes $a_{1}, a_{2}, \ldots . . a_{q}$. These attributes change with time and space due to causes that are natural as well as artificial (i.e., agent/developer influence).

$$
V_{i}=\left[a_{i 1} a_{i 2 \ldots \ldots \ldots \ldots . . . . .} a_{i q}\right] \quad \mathrm{V}_{\mathrm{i}} \text { is a vector of land attributes }
$$

2. Each agent has expectation/preference attributes such as transportation cost, tax policies, availability of skilled labor or industrial structure, etc. These attributes also change with space and time. 


$$
e_{j}=\left[e_{j 1} a_{j 2} \ldots \ldots \ldots \ldots . . . a_{j q}\right] \quad \text { Where, } \mathrm{e}_{\mathrm{j}} \text { represents expectation vector }
$$

3. A goodness of fit between land attributes and developer's expectation attributes serves as a proxy for the potential firm to migrate to a specific parcel of land. In other words, $F_{i j}$ is a proxy for the utility of firm ${ }_{j}$ for locating at a parcel of land $i$.

$$
F_{i j}=f\left(v_{i}, e_{j}\right)
$$

4. The neighborhood size, $\mathrm{S}$ for a parcel of land ${ }_{\mathrm{i}}$ (land parcels with similar goodness fit) increases. It is inversely proportional to carrying capacities, $\mathrm{C}_{\mathrm{i}}$, and proportional to time, $\mathrm{t}$.

$$
S_{i}=\left(\frac{1}{c_{i}}\right) s(t)
$$

5. Each developer has near-perfect information, $\mathrm{h}_{\mathrm{j}}$ about a parcel of land, $\mathrm{i}$, and is inversely proportional to the number of attribute, $\mathrm{q}$, and proportional to time, $\mathrm{t}$.

$$
h_{j}=\left(\frac{1}{q}\right) h(t)
$$

From equations (3.2.4) and (3.2.5), it can be derived that an agent $\mathrm{j}$ 's information, $\mathrm{h}_{\mathrm{j}}$, about the immediate neighborhood, $\mathrm{S}_{\mathrm{i}}$ of a parcel of land, $\mathrm{i}$ with attribute $\mathrm{q}$ and capacity constraint $\mathrm{C}$ is given by:

$$
h_{j}\left(s_{i}\right)=\frac{s(t) h(t)}{c_{i} q}
$$

The level of growth on parcel of land, i, is computed by the combined fitness of all agents located on the parcel of land.

$$
g_{i}=\sum_{j} f i j
$$

The rate of development on a parcel of land, i, is limited by the carrying capacity of the land, where $\mathrm{C}_{\mathrm{i}}$ is the carrying capacity for a parcel of land.

$$
r_{i}=\frac{\left[g_{i-c_{i}}\right]}{c_{i}}
$$


As stated in equation (3.2.1), each parcel (site) has q attributes. However, each attribute may have a possible $\mathrm{k}$ value. Therefore, for land covered by $\mathrm{n}$ parcels, the total number of configurations is given by the number of possible expectation vector, which is given by, $\mathrm{nq}^{\mathrm{k}}$.

A firm $\mathrm{j}$ with an expectation vector e will migrate to a parcel of land $\mathrm{i}$ with attribute vector $\mathrm{v}$, only if the critical number of attributes in both e and v matches. Agents/firms/developers migrate to what they perceive to be more attractive parcels. The new migrants have to search for a nearby site that matches the migrants' expectations. By doing so, the model tries to understand why growth poles emerge and evolve in a region.

\subsection{THEORY OF INVESTMENT LOCATION DECISION}

The most important decision in CRE investments is the choice of investment location. In regards to trade area analysis, to assess retail store location, William Reilly (1931) and David Huff (1963) are pioneers in modeling the business location decisions of investors. Their model is an application of the gravity model, which is based on Newton's Law of Gravity, to predict social interactions such as movements of people and merchandise between places.

Reilly applied the gravity model to investigate a break point on a line connecting two centers to determine customers who will go to one center and those who will go to the other. He considered population and distance as the two primary location references to determine the breaking point. This break point is a location where exactly half the population shops at either of the two cities. Therefore, if one of the cities is larger than the other, the boundary point lies near the smaller city. Likewise, if one moves closer to one city from the break point, it means that the city where one moves towards will exhibit trade dominance.

The modified Reilly's equation based on Converse's (1949) formulation is: 


$$
B_{m}=\frac{D_{m n}}{1+\sqrt{\frac{P_{n}}{P_{m}}}}
$$

Whereby,

$\mathrm{B}_{\mathrm{m}}=$ Break point distance for City $\mathrm{M}$

$\mathrm{D}_{\mathrm{mn}}=$ Distance between place $\mathrm{M}$ and place $\mathrm{N}$ (travel cost can be a substitute)

$\mathrm{P}_{\mathrm{n}}=$ Population of city $\mathrm{N}$

$\mathrm{P}_{\mathrm{m}}=$ Population of city $\mathrm{M}$

The model assumes a flat surface with no destructing features that may affect consumers' decision in which city to buy. Given this assumption, the ability to attract businesses between the two cities is directly proportional to the square root of the population of the cities and inversely proportion to the distance between these two cities.

The Huff model, which was introduced by David Huff in 1963, is an alternative model for trade area estimation. The model is widely used to predict consumers' spatial behavior in their store location decision. The premise of the model is that when an individual is faced with alternatives, the probability that a particular alternative will be selected depends on to the perceived utility of that specific alternative, as shown in the following equation:

$$
\text { 3.3.2 } \quad P_{a b}=\frac{U_{a b}}{\sum_{j=1}^{n} U_{b}}
$$

Where $\mathrm{P}_{\mathrm{ab}}$ is the probability that an individual, a, will select alternative b. $U_{a b}$, is the utility of alternative, $\mathrm{b}$ whereas, $\sum_{b=1}^{n} U_{b}$ is the sum of the utilities of all alternatives considered by the individual, a.

The model is also used to estimate the probability that a customer in a particular trade area, a, will shop at a particular store, $b$, using the following equation: 


$$
P_{a b}=\frac{S_{b} / T_{a b}{ }^{\theta}}{\sum_{j=1}^{n} \frac{S_{b}}{T_{a b} \theta}}
$$

Whereby,

$\mathrm{P}_{\mathrm{ab}}$ denotes the probability that an individual, a shops at location $\mathrm{b}$;

$\mathrm{S}_{\mathrm{b}}$ denotes the size of a shopping store at location $\mathrm{b}$;

$\mathrm{T}_{\mathrm{ab}}$ denotes the travel time that takes to get to location $\mathrm{b}$; and

$\theta$ is a parameter that reflects the effect of travel time. This parameter is estimated empirically.

The smaller the $\theta$, the smaller the effect of travel time on the probability that a customer will shop at a given center. This model can be adjusted based on different product types and can give a different trade area and sale forecasts.

The above model can also be modified to project the total number of customers that travel from a to shopping center $b$.

$$
\text { 3.3.4 } E_{a b}=P_{a b} * C_{a}
$$

Whereby,

$E_{a b}$ denotes the total expected number of shoppers at location a that probably travel to shops at location $b$, $\mathrm{C}_{\mathrm{a}}$ is the number of shoppers at a, and, $\mathrm{P}_{\mathrm{ab}}$ is the probability that individual a shops at $\mathrm{b}$.

The assigned model parameters help to control unique trading areas of products and services.

\subsection{LOCATION DECISION OF FIRMS AND COST OF PRODUCTION}

Spatial disparities of economic development to a great extent are determined by the location decisions of firms. These decisions of firms are highly dependent on both input price and 
market proximity, which in turn enables firms to reduce total cost. This section presents a model that explains firm's production location decisions that minimize total cost. The model is developed by Roback (1982) and examines the interaction of wages and rents to equalize total cost across locations. The model assumed that firms face a production function, $Q$ that interacts with wage and rents to minimize total cost of production. The production function is;

\subsection{1 $Q=f\left(l^{p}, n ; z\right)$}

Where, $\left(l^{p}\right)$ is land use, $(n)$ total number of workers, and $(z)$ endowed amenities ( $z$ can represent either "productive" or "unproductive" amenities) $)^{3}$ to produce good $Q$. In the case where, $r$, is price of land and $w$, wage rate, firms choose combination of workers $(n)$ and land used $\left(l^{p}\right)$ to minimize the total production cost as follow;

\subsubsection{Min $n w+l^{p} r$}

Subject to $Q=f\left(n, l^{p}, z\right)$

The solution of equation 3.4.2 gives demand functions for land and labor as follow;

$$
\begin{aligned}
& 3.4 .3 \quad l^{d}=l^{d}(w, r ; z) \\
& 3.4 .4 \quad n^{d}=n^{d}(w, r ; \mathrm{z})
\end{aligned}
$$

Since the model assumes a production function with a constant return to scale, the unit cost equals production cost at equilibrium. 3.4.5. $\mathrm{C}(w, r ; z)=1$

This means that locations with higher wage rates must lower the price of land (rent) to equalize cost across cities. If not, firms will be forced to locate their capital to other cities where they can reduce their cost and maximize their profit.

\footnotetext{
${ }^{3}$ In the model, "Productive" amenity is assumed to refer amenities that lower production cost (e.g. lack of severe snow storm ) whereas, "unproductive" amenity refers amenities that raise production cost (e.g. clean air)
} 


\section{CHAPTER 4. EMPIRICAL MODEL AND DATA DESCRIPTION}

Chapter 3 examined the theoretical relationship between commercial real estate investments and economic development. Regional growth models have been used to understand the process of how CRE investment brings economic development and how different economic and socio-demographic characteristics affect the investment location decision of investors and hence the economic benefits. Chapter 4 explains the empirical model used in this study and presents the data. The chapter is organized into six sections. Section 4.1 explains the non-spatial growth model. Section 4.2 presents non-spatial equations of population, employment, per capita income, and commercial real estate investment. Section 4.3 explains the spatial model. Section 4.4 presents spatial equations of population, employment, per capita income, and commercial real estate investment. Section 4.5 presents data and sources and the specification of variables used in the equations. Section 4.6 introduces the estimation technique package and summary of statistics.

\subsection{NON-SPATIAL MODEL}

As indicated earlier, the focus of this study is the relationship between commercial real estate investments, specifically retail establishments, and economic growth as represented by growth in population density, employment density, and per capita income. Beside the retail establishment variable, other economic variables are also included to understand their effects in determining relationships in the growth process. The empirical analysis of this study contains nonspatial and spatial models. The non-spatial model bases the two simultaneous equation model of Carlino and Mills (1987) which is also an extension of the work done by Steinnes (1982). The model applies regional adjustment and economic base theory to explore the relationship of population and employment simultaneously to regional growth. Deller et al. (2001) expanded the model into a three simultaneous equation model by introducing income into the model, and they 
examined the interdependencies among income, population, and employment changes. The empirical model of Deller et al. (2001) has been further extended to estimate the simultaneous relationships of economic development with entrepreneurship (Mojica, 2009; Bashir and Gebremedhin, 2012), amenities (Kahsai, 2009), and environmental regulation (Nondo, 2009). The model has also been used to model small business growth, migration behavior, local public services, and median household income (Gebremariam, 2006). This study extends the Deller et al. (2001) simultaneous equation model to a four simultaneous equation model to evaluate relationships among growth in the density of retail establishments, population density, employment density, and per capita income in the Northeast region.

The general form specifies the interaction between population density (POP), employment density (EMP), per capita income (PCI), and density of retail establishments (CRE) as follows:

(4.1.1a) $P O P^{*}=f\left(E M P^{*}, P C I^{*}, C R E^{*} / X^{P O P}\right)$

(4.1.1b) $E M P^{*}=f\left(P O P^{*}, P C I^{*}, C R E^{*} / X^{E M P}\right)$

(4.1.1c) $\mathrm{PCI}^{*}=f\left(P O P^{*}, E M P^{*}, C R E^{*} / X^{P C I}\right)$

(4.1.1d) $\mathrm{CRE} E^{*}=f\left(P O P^{*}, E M P^{*}, P C I^{*} / X^{C R E}\right)$

Where $P O P^{*}, E M P^{*}, P C T^{*}$, and $C R E^{*}$ are equilibrium levels of population, employment, per capita income, and retail establishments, respectively, in the ith county. The set of initial conditions and other predetermined variables that are expected to have either direct or indirect effects on population, employment, per capita income, and retail establishments are specified as $X^{P O P}, X^{E M P}, X^{P C I}$, and $X^{C R E}$, respectively. The general equilibrium forms explained in equations (4.1.1a) to (4.1.1d) can be expressed in a four variable linear relationship as: 
(4.1.2a) $P O P^{*}=\alpha_{0 P O P}+\beta_{1 P O P} E M P^{*}+\beta_{2 P O P} P C I^{*}+\beta_{3 P O P} C R E^{*}+\sum \delta_{1 P O P} X^{P O P}$

(4.1.2b) $E M P^{*}=\alpha_{0 E M P}+\beta_{1 E M P} P O P^{*}+\beta_{2 E M P} P C I^{*}+\beta_{3 E M P} C R E^{*}+\sum \delta_{2 E M P} X^{E M P}$

(4.1.2c) $\mathrm{PCI}^{*}=\alpha_{0 P C I}+\beta_{1 P C I} P O P^{*}+\beta_{2 P C I} E M P^{*}+\beta_{3 P C I} C R E^{*}+\sum \delta_{3 P C I} X^{P C I}$

(4.1.2d) $C R E^{*}=\alpha_{0 C R E} E+\beta_{1 C R E} P O P^{*}+\beta_{2 C R E} E M P^{*}+\beta_{3 C R E} P C I^{*}+\sum \delta_{4 C R E} X^{C R E}$

Mills and Price (1984) suggested that equilibrium levels of variables such as population, employment, per capita income, and investment in retail establishments should be adjusted with their distributed lags because they are likely to relate to their lagged values. The distributed lag adjustment models are specified as:

(4.1.3a) $P O P_{t}=P O P_{t-1}+\lambda_{P O P}\left(P O P^{*}-P O P_{t-1}\right)$

(4.1.3b) $E M P_{t}=E M P_{t-1}+\lambda_{E M P}\left(E M P^{*}-E M P_{t-1}\right)$

(4.1.3c) $\mathrm{PCI}_{t}=P C I_{t-1}+\lambda_{P C I}\left(P C I^{*}-P C I_{t-1}\right)$

(4.1.3d) $\mathrm{CRE}_{t}=C R E_{t-1}+\lambda_{C R E}\left(C R E^{*}-C R E_{t-1}\right)$

$P O P_{\mathrm{t}-1}, E M P_{\mathrm{t}-1}, P C I_{\mathrm{t}-1}$ and $C R E_{\mathrm{t}-1}$ represent the initial conditions of population, employment, per capita income, and investment in retail establishments and $\lambda_{P O P}, \lambda_{E M P}, \lambda_{P C I}$, and $\lambda_{C R E}$ represent the speed of adjustment coefficients adjusted to the desired level of population, employment, per capita income, and retail establishments. The values of the adjustment coefficients are assumed to be between 0 and $1: 0 \leq \lambda_{P O P}, \lambda_{E M P}, \lambda_{P C}, \lambda_{C R E} \leq 1$. Higher values indicate quicker growth rate.

Equations (4.1.3a) to (4.1.3d) indicate that the present condition of population density, employment density, per capita income, and density of retail establishments depend on their initial conditions and a change between equilibrium value and its lagged value. Change in the dependent variables by rearranging equations (4.1.3a) to (4.1.3d) yields the following equations: 
(4.1.4a) $\Delta P O P=P O P_{t}-P O P_{t-1}=\lambda_{P O P}\left(P O P^{*}-P O P_{t-1}\right) \Rightarrow P O P^{*}=\frac{1}{\lambda_{P O P}}\left(P O P_{t}-P O P_{t-1}\right)$

(4.1.4b) $\Delta E M P=E M P_{t}-E M P_{t-1}=\lambda_{E M P}\left(E M P^{*}-E M P_{t-1}\right) \Rightarrow E M P^{*}=\frac{1}{\lambda_{E M P}}\left(E M P_{t}-E M P_{t-1}\right)$

(4.1.4c) $\Delta P C I=P C I_{t}-P C I_{t-1}=\lambda_{P C I}\left(P C I^{*}-P C I_{t-1}\right) \Rightarrow P C I^{*}=\frac{1}{\lambda_{P C I}}\left(P C I_{t}-P C I_{t-1}\right)$

(4.1.4d) $\Delta C R E=C R E_{t}-C R E_{t-1}=\lambda_{C R E}\left(C R E^{*}-C R E_{t-1}\right) \Rightarrow C R E^{*}=\frac{1}{\lambda_{C R}}\left(C R E_{t}-C R E_{t-1}\right)$

where $\Delta$ represents a region's changes in growth rates of population density, employment density, per capita income, and retail establishment density. The changes in the dependent variables are calculated as the difference between the log values of the variables' final period $\left(\mathrm{T}_{2010}\right)$ and initial period $\left(\mathrm{T}_{2000}\right)$ as given below:

$$
\begin{array}{ll}
(4.1 .5 a) & \triangle P O P=\operatorname{LOG}\left(P O P_{2010}\right)-\operatorname{LOG}\left(P O P_{2000}\right) \\
(4.1 .5 b) & \triangle E M P=\operatorname{LOG}\left(E_{2010}\right)-\operatorname{LOG}\left(E M P_{2000}\right) \\
(4.1 .5 c) & \triangle P C I=\operatorname{LOG}\left(P C_{2010}\right)-\operatorname{LOG}\left(P C I_{2000}\right) \\
(4.1 .5 d) & \Delta C R E=\operatorname{LOG}\left(C R E_{2010}\right)-\operatorname{LOG}\left(C R E_{2000}\right)
\end{array}
$$

By substituting equations (4.1.4a) through (4.1.4d) in equations (4.1.2a) through (4.1.2d), respectively, and rearranging them, a linear form of the empirical estimation model for the four simultaneous equations can be obtained. The linear model explains population, employment, per capita income, and retail establishment equations, respectively, as follows: 
(4.1.6a) $\triangle P O P=\alpha_{0 P O P}+\beta_{1 P O P} \Delta E M P+\beta_{2 P O P} \Delta P C I+\beta_{3 P O P} \Delta C R E+\beta_{4 P O P} P O P_{2000}+\beta_{5 P O P} E M P_{2000}+\beta_{6 P O P} P C I_{2000}$ $+\beta_{7 P O P} C R E_{2000}+\sum \delta_{1 P O P} X^{P O P}+u_{1}$

(4.1.6b) $\Delta E M P=\alpha_{0 E M P}+\beta_{1 E M P} \Delta P O P+\beta_{2 E M P} \Delta P C I+\beta_{3 E M P} \Delta C R E+\beta_{4 E M P} P O P_{2000}+\beta_{5 E M P} E M P_{2000}+\beta_{6 E M P} P C I_{2000}$ $+\beta_{7 E M P} C R E_{2000}+\sum \delta_{2 E M P} X^{E M P}+u_{2}$

(4.1.6c) $\Delta P C I=\alpha_{0 P C I}+\beta_{1 P C I} \Delta P O P+\beta_{2 P C I} \Delta E M P+\beta_{3 P C I} \Delta C R E+\beta_{4 P C I} P O P_{2000}+\beta_{5 P C I} E M P_{2000}+\beta_{6 P C I} P C I_{2000}$ $+\beta_{7 P C I} C R E_{2000}+\sum \delta_{3 P C I} X^{P C I}+u_{3}$

(4.1.6d) $\Delta C R E=\alpha_{0 C R E}+\beta_{1 C R E} \Delta P O P+\beta_{2 C R E} \Delta E M P+\beta_{3 C R E} \Delta P C I+\beta_{4 C R E} P O P_{2000}+\beta_{5 C R E} E M P_{2000}$ $+\beta_{6 C R E} P C I_{2000}+\beta_{7 C R E} C R E_{2000}+\sum \delta_{4 C R E} X^{C R E}+u_{4}$

The endogenous variables $\triangle P O P, \triangle E M P, \triangle P C I$, and $\triangle C R E$ indicate growth rates of counties' population density, employment density, per capita income, and number of retail establishment density, respectively. $\mathrm{X}$ represents the exogenous variable vector while $u_{1}, u_{2}, u_{3}$, and $y_{4}$ are error terms. Initial period is the year of $\left(\mathrm{T}_{2000}\right)$. The structural model of Deller and Lledo (2007) and Deller et al. (2001) explained that the speeds of adjustment coefficients that are adjusted to the desired level of the dependent variables are embedded in $\alpha, \beta$, and $\delta$. The lag adjustment model assumes that the dependent variables are adjusted to their equilibrium levels over a period of time. Deller et al. (2001) explained that the speeds of adjustment coefficients that are adjusted to the desired level of the dependent variables are embedded in $\alpha, \beta$, and $\delta$. The lag adjustment model assumes that the dependent variables are adjusted to their equilibrium levels over a period of time.

The above model enables the estimation of the structural relationships in the short-term adjustments of growth in population density, employment density, per capita income, and retail establishment density, and long-term equilibriums ( $P O P^{*}, E M P^{*}, P C I^{*}$, and $\left.\mathrm{C} R E^{*}\right)$ while simultaneously separating the effects of growth in retail establishments on regional economic growth. 


\subsection{THE NON-SPATIAL EQUATIONS}

\subsubsection{Population Growth EQUATION}

The endogenous variable, growth in population density (GPOP), is calculated as the difference in the $\log$ values of population density of 2010 and 2000 in $^{\text {th }}$ county. Growth population density is described as a function of growth in employment density (GEMP), growth in per capita income (GPCI), growth in the density of retail establishments (GCRE), and the initial condition of dependent variables. The population equation contains other control variables such as percentage of non-white population (NONWTE), percentage of population living below the poverty (POVERTY), counties' median housing values $(C M H V)$, number of new private house permit (PHP), crime rate (CRIME), and dummy variables of metro (METRO) and metro adjacent counties (METROADJ).

It is hypothesized that the percentage of a county's non-white population (NONWTE) and population growth (GPOP) have a positive relationship as diversity of people can indicate different opportunities in counties. Percentage of population below poverty (POVERTY) also measures economic opportunities in counties and a higher poverty rate is expected to have a negative relationship with population growth. The county median housing value $(C M H V)$ can represent amenities and availability of goods and services in a county. High median housing value is hypothesized to have positive relationship with population density growth as it could indicate economic opportunities and services provided in an area.

The number of new housing permits $(P H P)$ is also expected to have positive relationship with growth in the population as new housing permits explain the attractiveness of counties to live in and the different goods and services available. Crime rate (CRIME) is hypothesized to have a negative relationship with population density; the safer the area is, the more likely people would 
choose to live in it. Moreover, higher population density may also reduce crime risks because more people in an area can mean a larger base of police officers.

The initial level of population will capture the dynamics of convergence or divergence of population growth in the region. Dummy variables of metropolitan counties (METRO) and counties adjacent to metropolitan areas (METROADJ) are also included to control differences in growth patterns caused by proximity to high-population centers and adjacency to metropolitan. Due to the presence of agglomeration economies, these variables are hypothesized to positively relate to population growth.

(4.2.1) GPOP $=\beta_{0}+\beta_{1} G E M P+\beta_{2} G C R E+\beta_{3} G P C I+\beta_{4} E M P B A S E+\beta_{5} P O P B A S E+\beta_{6} P O V E R T Y$ $+\beta_{7} P H P+\beta_{8} C M H V+\beta_{9} N O N W T E+\beta_{10}$ CRIME $+\beta_{11}$ METRO $+\beta_{12}$ METROADJ $+\varepsilon_{1}$

\subsubsection{Employment Growth Equation}

Growth in employment density is explained as the difference in the log values of employment density of 2010 and 2000 in the $\mathrm{i}^{\text {th }}$ county. Growth in employment density is defined as a function of growth in population (GPOP), growth in per capita income (GPCI), growth in retail establishment density (GCRE), and initial conditions of dependent variables. Some other control variables that are assumed to explain the employment growth variable are also included.

The control variables include per capita income tax (PCITAX), percentage of population with age of 25 years or over, with Bachelor's Degree or higher education (COLLD), active labor force (OPERATIVE) represented by percentage of population over 18 years and below 65 years, road density $(R O A D D E N)$, banking and saving institutions (CBSI), new housing permits (PHP), and dummy variables for metro counties (METRO) and metro-adjacent counties (METROADJ).

It is hypothesized that per capita income tax (PCITAX) has a positive relationship with employment growth as it is a major income source for government spending programs. Provision of local government spending programs such as education, highways, railroads, healthcare, and crime prevention etc., 
in turn, are expected to attract new investors and stimulate the economy.

Percentage of population ages of 25 years or over with bachelor's degree or higher education (COLLD) represents the human capital of a county. Human capital increases productivity and innovativeness that, in turn, is expected to increase employment growth. Active labor force (OPERATIVE) is also hypothesized to have positive relationship with employment growth since it can be a pulling factor for firms/investors to come and invest as it explains the available labor resource available in counties. New housing permits $(P H P)$ are expected to have a positive relationship with employment growth since increased housing construction could indicate the economic well-being of a county. Banking and saving institutions (CBSI) are also expected to have positive relationship with employment growth since those institutions confirm the accessibility of credit and loan that can, in turn, stimulate more investment and more jobs in a county.

It is hypothesized that road density (ROADDEN) has a positive relationship with employment growth as road density represents the transportation accessibility in a county; it is a very important infrastructural component in production as well as distribution phase of any investment. Dummy variables of metropolitan counties (METRO) and counties adjacent to metropolitan counties (METROADJ) are also included to control differences in growth pattern caused by proximity to high population centers and adjacency to metropolitan. Due to the presence of agglomeration economies, these variables are hypothesized to positively relate to additions in investments and new opportunities that can lead to employment growth.

(4.2.2) $G E M P=\beta_{0}+\beta_{1} G P O P+\beta_{2} G P C I+\beta_{3} C R E+\beta_{4} P O P B A S E+\beta_{5} P C I B A S E+\beta_{6} C R E B A S E+\beta_{7} P H P$ $+\beta_{8} C B S I+\beta_{9} R O A D D E N+\beta_{10}$ OPERATIVE $+\beta_{11}$ PCITAX $+\beta_{12} C O L L D+\beta_{13} M E T R O+\beta_{14} M E T R O A D J+\varepsilon_{1}$ 


\subsubsection{Per Capita Income Growth Equation}

Growth in per capita income is explained as the difference in the log values of per capita income of 2010 and 2000 in the $\mathrm{i}^{\text {th }}$ county. It is a function of dependent variables such as growth in population $(G P O P)$, growth in employment (GEMP), and growth in retail establishments (GCRE); the initial conditions of dependent variables; and some control variables.

The control variables include per capita income tax (PCITAX), percentage of retired population (RETIRE), density of number of firms (NFIRM), county's median housing value (CMHV).

Per capita income tax $(P C I T A X)$ is expected to have a positive relationship with per capita income growth. This is because per capita income tax can ultimately be used in the provision of local government spending programs such as education, healthcare, highways, railroads and crime prevention etc., which, in turn, are expected to stimulate the economy.

The percentage of retired labor force (RETIRE), which is represented by the percentage of population 65 years and above is expected to have negative relationship with per capita income because the main source of income for retired people is pension and government benefits.

It is expected that the density of the number of firms (NFIRM) has a positive relationship with per capita income growth. As the number of firms in a county increases, demand for labor also increases. The demand for labor increases job opportunities for unemployed or underemployed population that leads to growth in per capita income in the county. County's median housing value $(C M H V)$ is hypothesized to have positive relationship with per capita income growth. It can represent not only the spending capacity and living standard of people living in the county but also the different opportunities in a county.

Dummy variables of metropolitan counties (METRO) and counties adjacent to metropolitan counties (METROADJ) are also included to control differences in growth patterns 
that are caused by proximity to high-population centers and adjacency to metropolitan areas. Due to the presence of agglomeration economies, these variables are hypothesized to positively relate to per capita income.

(4.2.3) $G P C I=\beta_{0}+\beta_{1} G E M P+\beta_{2} G P O P+\beta_{3} G C R E+\beta_{4} C R E B A S E+\beta_{5} P O P B A S E+\beta_{6} P C I B A S E+\beta_{7} N F I R M$ $+\beta_{8} C M H V+\beta_{9}$ PCITAX $+\beta_{10}$ RETIRE $+\beta_{11} M E T R O+\beta_{12} M E T R O A D J+\varepsilon_{1}$

\subsubsection{Commercial Real Estate Growth Equation}

Retail establishment is used as one segment of commercial real estate investment. Growth in the density of retail establishments is explained as the difference in the log values of density of number of retail establishments of 2010 and 2000 in the $i^{\text {th }}$ county. Before analyzing the relationship, we must consider the possible differences in production technology and economies of scale between large and small retail store establishments that, in turn, are believed to differently affect regional economic growth. The CRE investment data, as represented by number of retail establishment, is classified to two categories based on employment size.

Investment in retail establishment is explained as a function of growth in population density (GPOP), growth in employment density (GEMP), and growth in per capita income (GPCI); the initial conditions of dependent variables; and some control variables.

Control variables are included to explain factors that further influence growth in retail establishments. These include government expenditure (EGOV), density of number of firms (NFIRM), county's median housing value $(C M H V)$, property tax on business $(P T A X)$, per capita income tax (PCITAX), poverty rate (POVERTY), road density (ROADDEN) and a dummy variable for metro counties (METRO) and adjacency to metro counties (METROADJ).

Median housing value $(C M H V)$ is used to compare real estate prices in different markets and is hypothesized to positively affect retail establishments because it brings a potential profit for 
commercial real estate owners in terms of high rent and resale value. High property tax on business (PTAX) is expected to negatively affect retail establishments as it is an additional cost for investors, buyers, and renters.

It is hypothesized that density of number of firms (NFIRM) has a positive relationship with retail establishments. New investments are expected to benefit highly from the agglomeration economy that arises from spatial proximity with nearby firms and that, in turn, encourage commercial real estate developers to invest.

The percentage of people living below the poverty line is expected to have a negative relationship with growth in retail establishments. A higher poverty level represents fewer households' spending ability and aggregate demand of people living in the surrounding areas that can discourage commercial real estate developers to invest. It is hypothesized that both per capita income tax (PCITAX) and government expenditure (EGOV) have a positive relationship with retail establishment growth. Per capita income tax can ultimately be used in the provision of local government spending programs that, in turn, are expected to stimulate the investment.

It is hypothesized that road density (ROADDEN) has a positive relationship with growth in retail establishments. Road density represents transportation accessibility in a county, and having higher interstate road density can encourage commercial real estate investors to invest. Metro areas (METRO) and counties adjacent to metro areas (METROADJ) are centers of economic and business activities and are expected to affect retail establishments positively.

(4.2.4) GCRE $=\beta_{0}+\beta_{1} G P O P+\beta_{2} G E M P+\beta_{3} G P C I+\beta_{4} C R E B A S E+\beta_{5} P O P B A S E$ $+\beta_{6} E G O V+\beta_{7} C M H V+\beta_{8} P C I T A X+\beta_{9} P T A X+\beta_{10} R O A D D E N+\beta_{11} N F I R M+$ $\beta_{12}$ POVERTY $+\beta_{13}$ METRO $+\beta_{14}$ METROADJ $+\varepsilon_{1}$ 


\subsection{Spatial Growth Model}

The non-spatial model ignores the role of space in the growth process. However, it is apparent to assume proximity to different economic activities creates markets that can explain the potential economic development of regions. The fact that each region is composed of multiple counties that influence one another indicates that the data from these counties likely show spatial dependence. This level of dependency is contingent up on how strong the market interactions are among counties and may stimulate or hamper development. This possible spatial dependency calls for the importance of developing spatial modeling in empirical analysis. Anselin (1988) argued that paying no attention to spatial dependency will yield biased or inefficient estimators. He showed that OLS estimation results will be inconsistent. LeSage and Fischer (2009) also pointed out the importance of recognizing a possible spatial dependence in terms of population, employment, and per capita income in regional economic growth analysis.

In relation to CRE investment, the decision to invest in an area may depend on the demand factors available in a county. If the demand factors are not fulfilled by a certain county, then the attractiveness of an area for a CRE investment will be under competition with neighboring counties, generating a negative spillover effect. On the other hand, the attractiveness of a county may increase the market in favor of neighboring counties through transfers of labor, knowledge, and other capital, generating a positive spillover effect. This spillover effect shapes the movement of labor and other regional growth factors that, at the end, determine the level of economic development in a county.

The Spatial Error Model (SEM) and the Spatial Autoregressive (SAR) model are the two most widely used econometric approaches for incorporating spatial dependency. The SAR model assumes that the value of the dependent variable of an area is dependent on the weighted average 
of the dependent variable of other nearby areas and other explanatory variables. On the other side, the spatial error model (SEM) assumes that spatial dependence is caused either by unmeasured variables that are correlated across space, which results in omitted variable misspecification error or the use of spatial data that does not match with the actual behavioral units being studied (Anselin, 1988). Thus, the correlation of a spatial error across variables is the general assumption of the model that violates the OLS assumption and thereby makes OLS estimates inefficient and biased.

The SAR model is:

$$
\text { (4.2.1) } Y=X \beta+\rho W Y+\varepsilon \quad \text { with } \quad \varepsilon \sim N\left(0, \sigma^{2} I\right)
$$

Where $Y$ is an $n \times 1$ vector of observations of the dependent variable, $X$ is the $n \times k$ design matrix of explanatory variables, $\beta$ is the $k \times 1$ vector of regression coefficient, $W$ is $n \times n$ spatial weight matrix, $\rho$ is parameter $(1 \times 1), W Y$ is the spatial lag of dependent variable, and $\mathcal{E}$ is the $n \times 1$ disturbance term and assumed to have a normal distribution with mean of zero.

The SEM model is

$$
\text { (4.2.2) } \quad Y=X \beta+\varepsilon
$$

Where $Y$ is an $n \times 1$ vector of observations of dependent variable, $X$ is the $n \times k$ design matrix of explanatory variables, $\beta$ is the $k \times 1$ vector of regression coefficient, and $\mathcal{E}$ is the $n \times 1$ disturbance term that follows:

$$
\text { (4.2.3) } \quad \varepsilon=\lambda W \varepsilon+\mu
$$

$W$ is $n \times n$ spatial weight matrix, $\lambda$ is parameter $(1 \times 1)$,and $\mu$ is the $n \times 1$ vector of innovations. Since it is not possible to include all relevant explanatory variables in a model and because dependent variables may exhibit spatial dependence, LeSage and Fischer (2009) explain that the 
correct model to use is one that includes both a spatial lag of the dependent variable and a spatial lag of the explanatory variables.

The Spatial Durbin Model (SDM) incorporates not only spatial lag of dependent variable but also the spatial lag of independent variables. LeSage and Fischer (2009) indicated that SDM also deals with omitted variable bias. The SDM is:

\section{(4.2.4) $\quad Y=\rho W Y+X \beta+\theta W X+\varepsilon$ with $\varepsilon \sim N\left(0, \sigma^{2} I\right)$}

Where $Y$ is the $n \times 1$ vector of observations of dependent variable, $X$ is the $n \times k$ design matrix of explanatory variables, $\beta$ is the $k \times 1$ vector of regression coefficient, $W$ is $n \times n$ spatial weight matrix, $\rho$ is parameter $(1 \times 1), \theta$ is the $k \times 1$ vector, $W X$ is the spatial lag of independent variables, and $\mathcal{E}$ is the $n \times 1$ disturbance term and assumed to have a normal distribution with a mean of zero.

\subsection{Spatial Model}

The use of the SDM implies that economic growth and retail establishments in a county is dependent upon the neighboring counties' economic and retail establishment growth variables, as well as the county's own explanatory variables. Following the above discussion, the SDM can be expressed as the extension of the non-spatial model equation 4.1.6a-4.1.6d. as follows: 
(4.4a) $\Delta P O P=\rho^{*} W \Delta P O P+\beta_{P P p}(I+W) \Delta E M+\beta_{2 P p p}(I+W) \Delta P C+\beta_{3 P p p}(I+W) \Delta C R E+\beta_{4 P p p}(I+W) P O P_{2000}+$ $\beta_{5 P p p}(I+W) E M_{2000}+\beta_{6 P p p}(I+W) P C_{2000}+\beta_{7 P p p}(I+W) C R E_{2000}+\sum \delta_{P p p}(I+W) X^{P p p}+u_{1}$

(4.4b) $\Delta E M P=\rho^{*} W \Delta E M+\beta_{E N P}(I+W) \Delta P O P+\beta_{2 E N P}(I+W) \Delta P C+\beta_{3 E M P}(I+W) \Delta C R E+\beta_{4 E N P}(I+W) P O P_{2000}+$ $\beta_{5 E M P}(I+W) E M P_{2000}+\beta_{6 E N P}(I+W) P Q_{2000}+\beta_{\text {IEn }}(I+W) C R E_{2000}+\sum \delta_{2 E n p}(I+W) X^{E \eta p}+u_{2}$

(4.4c) $\Delta P C=\rho^{*} W \Delta P C+\beta_{P G}(I+W) \Delta P O P+\beta_{2 P G}(I+W) \Delta E M P+\beta_{3 P G}(I+W) \Delta C R E+\beta_{4 P G}(I+W) P O P_{2000}+$ $\beta_{5 P G}(I+W) E M_{2000}+\beta_{6 P G}(I+W) P Q_{2000}+\beta_{7 P G}(I+W) C R E_{2000}+\sum \delta_{3 P G}(I+W) X^{P C}+u_{3}$

(4.4d) $\Delta C R E=\rho^{*} W \Delta C R E+\beta_{C K E}(I+W) \Delta P O P+\beta_{2 C E E}(I+W) \Delta E M+\beta_{3 C R E}(I+W) \Delta P C+\beta_{4 C E E}(I+W) P O P_{2000}+$ $\beta_{5 C R E}(I+W) E M P_{2000}+\beta_{6 C R E}(I+W) P Q_{2000}+\beta_{\text {ICRE }}(I+W) C R E_{2000}+\sum \delta_{4 C E E}(I+W) X^{(R E}+u_{4}$

Each of the four equations above are explained as a function of the dependent variables $\triangle P, \triangle E, \triangle P C I$, and $\triangle C R$, their initial conditions, other exogenous variables $\mathrm{X}$, and with their spatially weighted counterparts. I is the identity matrix, the terms $(\mathrm{I}+\mathrm{W})$ represent the spatial weights of the dependent and explanatory variables to reflect the own county values and the average of the surrounding counties. $\rho W$ denotes the spatial dependences of the dependent variables where, $\rho$ (rho) measures the strength of the spatial dependence and is the coefficient of the spatial lag of the dependent variables in each equation. $u_{1}, u_{2}, u_{3}$ and $u_{4}$ represent the residuals of growth in population, employment, per capita income and retail establishments, respectively.

\subsection{Data Type and Source}

The empirical model is used to analyze the effects of CRE investment in regional economic growth. The model is a system of equations with endogenous variables as a function of accessibility, economic, and socio-demographic variables. The study computes and uses growth in population density $(G P O P)$, employment density $(G E M P)$, per capita income $(G P C I)$, and density of retail establishments $(G C R E)$, from year 2000 to 2010 as endogenous variables. This 
research extends and builds upon a foundation of research on the Northeast region of the U.S. The region is large geographically and as such there is the potential for underlying processes to vary systematically across space. Given the broad range of variables in the analysis section, however, data availability dictates that county be used as units of analysis. The more expansive geographical region provides the opportunity to include a large enough number of observational units to support strong statistical inference. Although county-level units of analysis might also mask some withinregion variation, only a subset of the variables is available at finer levels of geographical detail.

Endogenous and exogenous variables included in the analysis are collected from the U.S. Census Bureau, County and City Data Book (C\&CDB), Bureau of Economic Analysis (BEA), U.S. Department of Agriculture's Economic Research Services (ERS), WVU Natural Resource Analysis Center (NRAC), U.S. Census Bureau's Statistics of U.S. Businesses (SUSB), and Business Pattern Statistics. All variables that are included in the empirical analysis and their sources are summarized in Table 4.5 below. 
TABLE 4.5 DEFINITION OF VARIABLES AND SOURCE

\begin{tabular}{|c|c|c|}
\hline Variable & Definition & Source \\
\hline \multicolumn{3}{|c|}{ Endogenous variables } \\
\hline GPOP & Growth in population density per county & EBA \\
\hline GEMP & Growth in employment density per county & EBA \\
\hline GPCI & Growth in per capita income per county & $\mathrm{C} \& \mathrm{CD}$ \\
\hline GCRE & Growth in number of retail establishments density per county & SUSB \\
\hline \multicolumn{3}{|c|}{ Initial Conditions } \\
\hline POPBASE & County population density in 2000 & USCB \\
\hline EMPBASE & County employment density in 2000 & EBA \\
\hline PCIBASE & County per capita income in 2000 & $\mathrm{C} \& \mathrm{CD}$ \\
\hline CREBASE & County number of retail establishment density in 2000 & USBS \\
\hline \multicolumn{3}{|c|}{ Accessibility variables } \\
\hline METRO & Metropolitan counties, dummy variable $=10$ otherwise & ERS \\
\hline METROADJ & Counties are adjacent to metro areas, dummy variable $=1,0$ & ERS \\
\hline ROADDEN & Interstate road density & NRAC \\
\hline \multicolumn{3}{|c|}{ Economic variables } \\
\hline NFIRMS & Density of number of firms per county & USBS \\
\hline PCITAX & Per capita income tax & $\mathrm{C} \& \mathrm{CD}$ \\
\hline PTAX & Property tax on business & USCB \\
\hline POVERTY & Percent of families below poverty line & USCB \\
\hline CMHV & County's median housing value & C\&CD \\
\hline EGOV & Per capita government expenditure & C\&CD \\
\hline PHP & Density of housing permits & C\&CD \\
\hline CBSI & Density of banking and saving institutions & C\&CD \\
\hline \multicolumn{3}{|c|}{ Demographic variables } \\
\hline RETIRE & Percent of population above 65 & C\&CD \\
\hline NONWTE & Percent of non-white people & C\&CD \\
\hline OPERATIVE & Percentage of population between 16 years and 64 years & $\mathrm{C} \& \mathrm{CD}$ \\
\hline COLLD & Percentage of population 25 years and older with college degree & $\mathrm{C} \& \mathrm{CD}$ \\
\hline CRIME & Serious crime rate & C\&CD \\
\hline
\end{tabular}

\subsection{Estimation Method}

The non-spatial simultaneous equation model explained by equations (4.1.6a) through (4.1.6d) is estimated using three Stages Least Square (3SLS) simultaneous estimation techniques.

The spatial equation model explained by equations (4.4a) through (4.4.d) is estimated using the SDM and SAR model using the codes provided by LeSage's Econometrics MATLAB toolbox. 
Table 4.6 presents the summary statistics of the explanatory and endogenous variables used in the model. Column 2 shows variable measurement type, column 3 shows the average values of the variables, columns 3 and 4 show the minimum and maximum values of the variables, respectively, and column 5 shows the standard deviation.

TABle 4. 6 Descriptive Statistics for the Northeast Counties, 2000-2010

\begin{tabular}{|l|l|l|l|l|l|}
\hline Variable & Unit & Mean & Min & Max & Std. \\
\hline EMPBASE & Log & 4.198298 & 0.021626 & 11.60433 & 1.72415 \\
\hline POPBASE & Log & 5.134251 & 1.139951 & 11.11183 & 1.576341 \\
\hline SCRIBASE & Log & -0.34118 & -3.78675 & 6.214782 & 1.551032 \\
\hline LCRIBASE & Log & -3.94782 & -8.28557 & 1.764086 & 1.897176 \\
\hline METRO & Level & 0.548495 & 0 & 1 & 0.498477 \\
\hline METROADJ & Level & 0.314381 & 0 & 1 & 0.465047 \\
\hline RETIRE & Percentage & 14.61164 & 7.451522 & 23.06844 & 2.68193 \\
\hline COLLD & Percentage & 20.58963 & 5.6 & 54.6 & 9.360455 \\
\hline NONWTE & Percentage & 9.624415 & 0.6 & 73 & 12.03228 \\
\hline CBSI & Log & 3.429119 & 0 & 6.137727 & 1.245616 \\
\hline MHI & Log & 10.58013 & 9.795178 & 11.29513 & 0.260887 \\
\hline POVERTY & Percentage & 9.042295 & 6.2186 & 13.17816 & 1.200554 \\
\hline CMHV & Log & 11.49728 & 10.02571 & 13.81551 & 0.444443 \\
\hline EGOV & Log & 12.80363 & 0 & 17.67069 & 2.005463 \\
\hline OPERATIVE & Log & 10.87592 & 7.951559 & 14.23433 & 1.324862 \\
\hline ROADDEN & Log & 6.793939 & 4.607495 & 9.318369 & 0.683881 \\
\hline NFIRM & Log & 8.840978 & 5.666427 & 12.55093 & 1.361568 \\
\hline PHP & Log & 5.396302 & 0 & 8.636397 & 1.884082 \\
\hline CRIME & Log & 7.28688 & 0 & 12.62136 & 1.835308 \\
\hline PTAX & Log & 6.683851 & 0 & 8.445268 & 0.965015 \\
\hline PCITAX & Log & 2.579631 & 0.992366 & 5.727921 & 0.937184 \\
\hline
\end{tabular}




\section{CHAPTER 5. EMPIRICAL RESULTS AND ANALYSIS}

The main purpose of this chapter is to empirically estimate the relationship between growth in CRE investment, specifically retail store establishments and regional economic growth in the Northeast region of the United States. Growth in population density, employment density, and per capita income are used as indicators of regional economic growth. The density of number of retail establishments is used to represent one segment of CRE investment in each county. This chapter consists of the result of both the spatial and the non-spatial models presented in chapter 4. Section 5.1 discusses the difference between the small and large CRE models. Section 5.2 presents the results of non-spatial model, and finally Section 5.3 presents the results of the spatial model.

\subsection{SIZE OF COMMERCIAL REAL EST ATE INVESTMENT}

To consider possible differences in production technology and economies of scale between large and small retail store establishments that, in turn, are believed to differently affect regional economic growth, the CRE investment data represented by number of retail establishments is classified to two categories based on employment size.

The employment size class of (1-19) employees is used to represent relatively small retail establishments, whereas those retail establishments that have 20 and more employees are considered as relatively large establishments. The employment size class of (1-19) is used as a cutoff employment size to differentiate small versus large retail store establishments for two main reasons. The first reason is that the study is interested to examine the economic effects of small employment size category establishments that are assumed to include most of the locally owned stores. The second reason is that if a cutoff point higher than 20 employees is considered, so many counties will be eliminated from the data set in the large category because they lack having a single retail store establishment that has 20 or more employees. This will cause an unbalanced number 
of counties between the two categories that will make comparison difficult. Before proceeding, it should be noted that the terms "small" and "large" are relative and generally may depend on industry type.

\subsection{Non-Spatial Growth Model Results}

The non-spatial model is used to analyze the relationship between economic growth and CRE investment. The number of retail establishments is used to represent one segment of CRE investment, whereas economic growth is represented by growth in population density, employment density, and per capita income. A three-stage least square (3SLS) simultaneous equation model is used in this analysis. The three-stage least square (3SLS) is used to overcome the problem of correlation in the error term across each equation and accounts all parameter restrictions in the system of simultaneous equations.

First, the small retail establishment data set of the Northeast region of the United States is used to examine the effects of small establishments on economic growth. Second, the large retail establishment data is used to evaluate the effects of large establishments on economic growth. The first columns of Tables 5.2.1-5.2.4 represent the results of a three stage least square using a system of simultaneous equation for the small commercial real estate model (SCRE). The second columns of Tables 5.2.1-5.2.4 represent the results of the large commercial real estate model (LCRE).

\subsubsection{Population Density Growth EQUATION}

The result of population density growth equation for the Northeast region using 3SLS is presented in Table 5.2.1. The population density growth equation is estimated against endogenous variables of growth in employment density $(G E M P)$, per capita income $(G P C I)$, and density of retail establishments (GCRE). The initial conditions of population density (POPBASE) and employment density (EMPBASE), and control variables are included to measure economic effects. 
An assumption is made in developing the empirical model that growth depends on initial conditions. The overall fit $\left(\mathrm{R}^{2}\right)$ of the empirical results for the population density equations are 60 and 43 percent in the small and large commercial real estate models, respectively.

The empirical results show that growth in population density $(G P O P)$ is positively and significantly related to growth in employment $(G E M P)$ in both models. This explains that an increase in the number of jobs also increases population growth—people follow jobs.

Table 5.2.1. Three Stage Least Square Results of Growth in Population Density

\begin{tabular}{|c|c|c|c|c|}
\hline \multirow[t]{2}{*}{ Variables } & SCRE & & LCRE & \\
\hline & Coefficient & $z$ & Coefficient & $z$ \\
\hline GEMP & $0.492^{* * *}$ & 5.51 & $0.519 * * *$ & 6.94 \\
\hline GCRE & $0.221 * * *$ & 3.26 & $-0.384 * * *$ & -8.12 \\
\hline $\mathrm{GPCl}$ & $-0.344 * * *$ & -3.72 & $-0.180 * *$ & -2 \\
\hline EMPBASE & 0.015 & 1.18 & 0.014 & 1.31 \\
\hline POPBASE & $-0.028 * *$ & -1.9 & $-0.029 * *$ & -2.25 \\
\hline POVERTY & -0.007 & -1.07 & -0.002 & -0.32 \\
\hline PHP & 0.003 & 1.04 & 0.000 & 0.02 \\
\hline CMHV & $0.024 * * *$ & 7.81 & $0.019 * * *$ & 6.39 \\
\hline NONWTE & $0.001^{* * *}$ & 2.45 & $0.001^{* *}$ & 1.89 \\
\hline CRIME & 0.002 & 0.82 & 0.002 & 1.18 \\
\hline METRO & -0.002 & -0.31 & 0.003 & 0.41 \\
\hline METROADJ & -0.006 & -0.79 & -0.007 & -0.91 \\
\hline $\mathrm{R}^{2}$ & 0.604 & & 0.425 & \\
\hline $\mathrm{N}$ & 299 & & 299 & \\
\hline
\end{tabular}

There is a positive and significant relationship between population growth (GPOP) and small commercial real estate investment (SCRE). This can imply that growth in SCRE investment increases the attractiveness of an area to live by increasing access to goods and services and job opportunities. However, growth in the density of large commercial real estate (LCRE) showed an unexpected negative relationship with growth in population density $(G P O P)$. This unexpected result, however, could mean that LCRE investments choose to locate more in low-population 
density areas such as suburbs because they require larger space/land; this can apply particularly to suburban shopping malls. However, locating in low-population density areas doesn't mean their market is restricted since most of large establishments have integrated supply scheme including online marketing to reach outside customers. The boost in online retailing created opportunities for retail stores located in low population density areas to pull a larger market presence from metropolitan areas. This statement is supported by Kim and Orazem (2012) finding that broadband availability has a significant positive firm entry effect in rural areas.

Growth in per capita income (GPCI) and growth in population density (GPOP) has a negative and significant relationship. This result may imply that income growth is not keeping up pace with population growth. In other words, larger supply of labor compared to new jobs can cause average per capita income to decrease.

The initial condition of population (POPBASE) has a negative and significant relationship with population growth $(G P O P)$. This relationship implies that counties that have initial higher numbers of population density in 2000 are growing slower compared to areas that have low initial population density. This gives support to the convergence of population density. A county's nonwhite population size (NONWTE) and growth in population (GPOP) are significantly and positively related to each other. Higher non-white population size can indirectly indicate economic opportunities in counties and leads to not only to the movement of people that have different racial background but also encourages inflow of new immigrants. Higher birth rates among most nonwhite population can also be another reason for the positive relation.

Counties' median housing value (CMHV) has a positive and significant relationship with growth in population (GPOP) in both models. Though it might be difficult to conclude the relationship between housing value and population growth, it can be argued that a median house 
value can represent amenities and opportunities in counties that potentially attract people to migrate in. The related demand for housing in those areas can be a reason for higher prices. Therefore, the positive relationship perhaps can mean that people increasingly want to migrate to more economically vibrant counties where housing price is high due to the productivity advantage of those areas.

\subsubsection{EMPLOYMENT GROWTH EQUATION}

The result of the employment growth equation for the Northeast region using 3SLS is presented in Table 5.2.2. The employment growth equation is estimated against endogenous variables of growth in population density $(G P O P)$, per capita income (GPCI), and density in commercial real estate investment $(G C R E)$. The initial conditions of population density (POPBASE), commercial real estate (CREBASE), per capita income (PCIBASE), and control variables are included to measure economic effects. An assumption is made in developing the empirical model that growth depends on initial conditions. The overall fit $\left(\mathrm{R}^{2}\right)$ of the empirical results for employment density equations are 42 and 33 in the small and large CRE models, respectively.

Growth in employment density $(G E M P)$ is positively and significantly related with growth in population density $(G P O P)$ in both models. This result indicates that job follows people. The initial level of population density $(P O P B A S E)$ also has a positive and significant relationship with growth in employment density (GEMP) in the small commercial real estate investment model (SCRE).

Growth in per capita income $(G P C I)$ has a positive and significant relationship with growth in employment (GEMP) in both models as expected. It implies that as the average earnings increases, it also induces more job opportunities leading to employment growth. 
Table 5.2.2.Three Stage Least SQuare Results of Growth in EMPloyment

\begin{tabular}{|l|l|l|l|l|}
\hline \multirow{2}{*}{ Variables } & SCRE & & LCRE & \\
\cline { 2 - 5 } & Coefficient & & Coefficient & z \\
\hline GPOP & $0.830^{* * *}$ & 4.86 & $1.071^{* * *}$ & 6.67 \\
\hline GPCI & $0.618^{* * *}$ & 4.61 & $0.626^{* * *}$ & 4.82 \\
\hline GCRE & 0.150 & 1.33 & $0.305^{* * *}$ & 3.18 \\
\hline POPBASE & $0.019^{* * *}$ & 2.39 & 0.036 & 1.58 \\
\hline PCIBASE & $0.000^{*}$ & -1.77 & 0.010 & 0.54 \\
\hline CREBASE & 0.003 & 0.55 & $0.010^{*}$ & 1.68 \\
\hline PHP & -0.002 & -0.19 & 0.013 & 0.81 \\
\hline CBSI & -0.011 & -0.73 & -0.015 & -0.98 \\
\hline ROADDEN & -0.019 & -1.53 & $-0.040^{* *}$ & -2.32 \\
\hline OPERATIVE & $-0.019 * * *$ & -3.33 & $-0.019 * * *$ & -3.31 \\
\hline PCITAX & 0.000 & 0.3 & 0.001 & 1.3 \\
\hline COLLD & 0.009 & 0.72 & 0.007 & 0.55 \\
\hline METRO & -0.012 & -1.02 & -0.004 & -0.3 \\
\hline METROADJ & 0.830 & 4.86 & 1.071 & 6.67 \\
\hline \multicolumn{5}{|l|}{} \\
\hline$R^{2}$ & 0.424 & 299 & 0.330 & \\
\hline N & Note: $* * * * * *$ \\
\hline
\end{tabular}

Growth in the density of large commercial real estate $(G C R E)$ has the expected positive and significant relationship with growth in employment density (GEMP). This signifies the positive economic role of CRE investments in stimulating and creating businesses and jobs. The initial level of large CRE investment also has a positive and significant relationship with growth in employment density (GEMP).This may imply that the initial condition of LCRE investment has a vital role in creating jobs and attracting capital to enhance employment growth and brings longterm economic impacts. However, growth in the density of SCRE investment and its initial condition showed a positive but insignificant relationship with growth in employment density $(G E M P)$. This result can be due the fact that small businesses were the hardest hit during the great recession and lost greater share of their employment compared to larger business.

The percentage of population between 16 and 64 years (OPERATIVE) represents the 
working-age population and has shown an unexpected negative and significant relationship with growth in employment density $(G E M P)$. Based on the assumption that rural counties tend to have a high rate of out-migration of youth that leaves a higher percentage of older residents behind, this negative relationship could be related to the job loss trend during the great recession as most of rural counties were less affected. As a result, counties with high a percentage of "operative" population may show a decrease in employment growth. The negative relationship of road density variable (ROADDEN) with growth in employment density in the large CRE investment model can also be justified by the job loss trend during the great recession.

\subsubsection{Per Capita Income Growth Equation}

The results of the per capita income growth equations for the Northeast region using 3SLS are presented in Table 5.2.3. The per capita income growth equation is estimated against endogenous variables of growth in population density (GPOP), growth in employment density (GEMP) and growth in retail establishments density (GCRE); the initial conditions of population (POPBASE), per capita income (PCIBASE) and CRE investment (CREBASE); and control variables are included to measure economic effects. The overall fit $\left(\mathrm{R}^{2}\right)$ of the empirical results for the per capita equations is 97 and 96 percent in the small and large CRE models, respectively.

Growth in employment density has the expected positive and significant relationship with growth in per capita income in both models, implying more jobs mean more earnings to a county. Growth in population $(G P O P)$ has a negative and significant relationship with growth in per capita income (GPCI) in both models. This observed negative relationship can be due to the fact that average county income is not keeping up with growth in population density pace. It can also imply surplus of labor. The initial level of population density (POPBASE) has also a positive and significant relationship with growth in per capita income (GPCI) in the large commercial real 
estate model. This confirms the theory that supports population as an economic stimulant, by providing the consumer demand to generate economies of scale in the production.

Table 5.2.3. Three Stage Least Square Results of Growth in Per Capita Income

\begin{tabular}{|l|l|l|l|l|}
\hline \multirow{2}{*}{ Variable } & SCRE & & LCRE & \\
\cline { 2 - 5 } & Coefficient & $\mathbf{z}$ & Coefficient & $\mathbf{z}$ \\
\hline GEMP & $0.571^{* * *}$ & 5.44 & $0.320^{* * *}$ & 3.13 \\
\hline GPOP & $-1.151^{* * *}$ & -8.24 & $-0.576^{* * *}$ & -3.71 \\
\hline GCRE & -0.130 & -0.93 & $0.510^{* * *}$ & 4.57 \\
\hline POPBASE & -0.010 & -1.87 & $0.072^{* * *}$ & 5.07 \\
\hline PCIBASE & -0.047 & -1.26 & $0.061^{* * *}$ & 4.3 \\
\hline CREBASE & 0.000 & -0.09 & $-0.122^{* * *}$ & -3.38 \\
\hline NFIRM & 0.002 & 0.2 & $0.016^{* *}$ & 2.15 \\
\hline CMHV & $0.080^{* * *}$ & 2.57 & $0.094^{* * *}$ & 3.38 \\
\hline PCITAX & 0.008 & 1.54 & $0.017^{* * *}$ & 3.02 \\
\hline RETIRE & $-0.004^{* *}$ & -2.14 & $-0.004^{* *}$ & -2.09 \\
\hline METRO & $-0.017^{*}$ & -1.65 & $-0.032^{* * *}$ & -2.89 \\
\hline METROADJ & 0.005 & 0.52 & 0.010 & 0.95 \\
\hline \multicolumn{5}{|l|}{} \\
\hline$R^{2}$ & 0.965 & \multicolumn{5}{|l}{} \\
\hline N & 299 & 0.957 & \\
\hline Note: $* * * * * *$ \\
\hline
\end{tabular}

The initial condition of per capita income (PCIBASE) has a positive relationship with growth in per capita income (GPCI) in the LCRE model. This positive and significant relationship suggests that counties with initial higher average income experienced greater income growth than counties with initial lower income.

Growth in the density of large CRE investment (GCRI) has a positive and significant relationship with growth in per capita income growth (GPCI), while growth in density of SCRE investment has an insignificant relationship. The positive relationship of LCRE implies that the investment is contributing to the earning and wellbeing of the economy. This result is also supported by the positive relationship the investment has with growth in employment density (GEMP). The insignificant relationship observed with SCRE investment could be contributed by 
the insignificant relationship observed with growth in employment density $(G E M P)$. Moreover, the strong positive effect of SCRE investment on growth in population density may also lessen the positive effect of the investment on growth in per capita income as long as the effect on population growth is higher than income growth.

The initial condition of LCRE investment showed a negative relationship with growth in per capita income. This could be related to the negative relationship the initial condition of CRE investment showed with growth in CRE investment $(G C R E)$ in the commercial real estate equation in Table 5.2.4.

The density of number of firms (NFIRM) in a county has a positive and significant relationship with per capita income growth $(G P C I)$ in the LCRE investment model. This implies that as the density of number of firms increase in a county, demand for labor also increases. Increased job opportunities for unemployed or under-employed in a county lead to an increase in per capita income. This relationship has an insignificant relationship in the SCRE investment model. A county's median housing value $(C M H V)$ has the expected positive relationship with growth in per capita income (GPCI). CMHV can represent not only the quality of life and the spending capacity of people living in a county but also, different opportunities. So, having higher median housing value can relate to higher income population and/or higher job opportunities, which leads to growth in per capita income (GPCI).

Per capita income tax is a major source of government revenue. The positive relationship between per capita income growth and per capita income tax implies that an increase in per capita income tax can ultimately be used as a source of money for government provisions such as education, healthcare, highways, railroads, crime prevention etc., which, in turn, are expected to stimulate the economy. 
Percentage of retired population showed expected negative and significant relationship with per capita income growth in both models. This could be due to the fact that the main sources of income for retired people are pensions and government benefits.

Dummy variable for metro (METRO) is significant with an unexpected negative sign in relation to growth in per capita income in both models; however, the magnitude is too small to explain.

\subsubsection{Commercial Real Estate Equation}

The result of the CRE investment growth equation for the Northeast region using 3SLS is presented in Table 5.2.4. The CRE growth equations are estimated against endogenous variables of growth in population density (GPOP), per capita income (GPCI), and employment density (GEMP); the initial condition of commercial real estate density (CREBASE) and population density (POPBASE); and control variables are included to measure economic effects. The overall fit $\left(\mathrm{R}^{2}\right)$ of the empirical results for CRE equations are 47 and 37 for the small and large CRE models, respectively.

Growth in population density $(G P O P)$ has a strong positive and significant relationship with growth in the density of SCRE investment. This implies that population is an important pulling factor that ensures the buying power of a certain county and it represents a strong aggregate demand for goods and services.

However, growth in population density has an unexpected negative and significant relationship with growth in the density of LCRE investment. This implies that LCRE investments choose to locate in areas where there is less population density. This could be due the large space/land requirement of these investments that may be difficult to find in densely populated areas. However, even when these LCRE investments are located in a less densely populated area, 
they may still be able to reach the outside markets because of their integrated marketing scheme, including online marketing compared to SCRE investments. The boost in online retailing can create a great opportunity for retail stores located in low population density areas to pull a larger market presence from metropolitan areas. This assumption is supported by Kim and Orazem (2012) finding that broadband availability has a significant positive firm entry effect in rural areas.

Table 5.2.4.Three Stage Least Square Results of Growth in Commercial Real Estate

\section{INVESTMENT}

\begin{tabular}{|l|l|l|l|l|}
\hline \multirow{2}{*}{ Variable } & SCRE & & LCRE & \\
\cline { 2 - 5 } & Coefficient & $\mathbf{Z}$ & Coefficient & Z \\
\hline GPOP & $0.814^{* * *}$ & 3.03 & $-1.516^{* * *}$ & -7.66 \\
\hline GEMP & 0.273 & 1.39 & $0.644^{* * *}$ & 4.42 \\
\hline GPCI & 0.462 & 1.53 & 0.025 & 0.12 \\
\hline CREBASE & 0.000 & 0.43 & $-0.060^{* * *}$ & -3.02 \\
\hline POPBASE & -0.011 & -0.7 & $-0.080^{* * *}$ & -3.46 \\
\hline EGOV & -0.007 & -0.88 & $0.011^{* *}$ & 2.06 \\
\hline CMHV & $0.064 * *$ & -2.83 & $0.054^{* * *}$ & 2.97 \\
\hline PCITAX & 0.005 & 0.5 & -0.007 & -0.99 \\
\hline PTAX & -0.001 & -0.07 & -0.010 & -0.91 \\
\hline ROADDEN & 0.042 & 1.27 & 0.001 & 0.03 \\
\hline NFIRM & $0.069 * * *$ & 2.39 & $-0.035^{*}$ & -1.68 \\
\hline POVERTY & -0.036 & -1.23 & 0.020 & 0.97 \\
\hline METRO & 0.010 & 0.55 & 0.018 & 1.1 \\
\hline METROADJ & 0.028 & 1.58 & -0.017 & -1.06 \\
\hline$R^{2}$ & 0.467 & & 0.366 & \\
\hline N & 299 & & 299 & \\
\hline Note: $* * * * * *$ & represents significance at $1,5,10 \%$, respectively & \\
\hline
\end{tabular}

The initial level of population density also showed a negative relationship with growth in LCRE investment. Growth in employment density (GEMP) showed the expected positive and significant relationship with large commercial real estate investment (GLCRE). The initial condition of CRE investment showed a negative and significant relationship with growth in CRE investment (GCRE). This result implies that counties that had low level of CRE investment in 2000 
had higher CRE growth rate compared to counties that had a higher level. This may also indicate the existence of location trend shifts among large retail establishment over this period of time.

Counties' median housing value $(C M H V)$ has the expected positive and significant relationship with growth in the density of large CRE investment (GCRE). This implies that counties' median housing value is one of the determinant factors in property appreciation rate and provides exclusive insight for CRE investors on how good the real estate market will likely be in the future.

Firm density (NFIRM) has a positive and significant relationship with growth in SCRE investment and a negative and significant relationship with LCRE investments. This result could imply that LCRE investments are less dependent on outside suppliers because of their fully integrated marketing scheme than SCRE investments. On the other hand, smaller investments will benefit highly from the agglomeration economy that arises from spatial proximity.

One of the fiscal factors likely to affect CRE investment is government expenditure $(E G O V)$. Government expenditure showed a positive and significant relationship with LCRE investment. The positive relationship can be constructed to mean that an increase in government expenditure can ultimately mean provision of expanded programs such as education, healthcare, highways, railroad, crime prevention etc. that, in turn, is expected to stimulate investment. The other fiscal variables regressed against growth in CRE are property tax (PTAX) and per capita income tax (PCITAX), both of them showed an insignificant relationship with growth in CRE.

\subsection{Spatial Model Results}

It was discussed earlier that the statistical analysis of regional data collected in reference to points in space tended to be similar to those from nearby locations. In such instances, ignoring spatial dependence in a regression is not reasonable and empirical results will be biased and 
inconsistent. This section provides the estimation results of spatial model developed in section 4.4. The Spatial Durbin Model (SDM) analyzes spillover effects by including spatial lags for dependent and independent variables. The model captures the direct and indirect effects of socio-economic variables in the regional development process. Whereas, the SAR model assumes that the value of the dependent variable of an area is dependent on the weighted average of the dependent variable of other nearby areas and other explanatory variables.

The issue of spillover effects, together with simultaneity of regional economic growth indicators, creates a challenge in the estimation. Neither the current MATLAB code that is used to estimate this models nor $\mathrm{R}$ have the internal capability of estimating spatial models in a simultaneous equations model. As a result, each of the equations in the model is estimated separately as a function of endogenous dependent variables, spatially weighted dependent variables, independent variables, and spatially weighted independent variables.

The Lagrangian Multiplier (LM) test is used to test spatial dependency in the observation and for the purpose of model specification. The LM test suggested SAR model for the population density growth equation and SDM for the per capita income equation. The employment density and CRE investment equations showed no spatial dependency suggesting that the non-spatial estimation model is the right fit for them. The result of the LM test is attached at the annex section (annex 1).

The interpretation of the coefficients in the spatial model is in such a way that changes in the independent variables $\mathrm{x}_{\mathrm{i}}$ are represented by a direct effect on the county's marginal regional economic development and a spatial spillover effect on the neighboring county's marginal regional economic development (indirect effect). Since the plan of this estimation is to understand the spatial effects of the variables on regional economic growth, emphasis will be given on the 
estimated direct, indirect, and total effects instead of the estimated coefficients of the model. The strength of the estimated spatial correlation is shown as measured by rho $(\rho)$ in Table 5.3.

Table 5.3: Estimated Value of the Spatial Dependence Statistic, RHO

\begin{tabular}{|l|l|l|l|l|}
\hline & \multicolumn{2}{|l|}{$\begin{array}{l}\text { Small Commercial Real } \\
\text { Estate Investment Model }\end{array}$} & \multicolumn{2}{l|}{$\begin{array}{l}\text { Large Commercial Real } \\
\text { Estate Investment Model }\end{array}$} \\
\hline Equations & Rho & P-level & Rho & P-level \\
\hline GPOP & 0.151 & 0 & 0.172 & 0 \\
\hline GEMP & No Spatial & & No Spatial & - \\
\hline GPCI & 0.177 & - & 0.172 & 0 \\
\hline GCRE & No Spatial & - & No Spatial & - \\
\hline N & 299 & & 299 & \\
\hline
\end{tabular}

\subsubsection{Population Density Growth Equation}

The results of the Spatial Autoregressive Model for the population growth equation are presented in Table 5.3.1. The first column of the table explains the result of the small commercial real estate investment model and the second column explains the result of the large commercial investment model. The statistically significant values, $(0.151)$ and $(0.172)$ of the spatial measure (Rho), indicate spatial dependency among counties in both small and large CRE models, respectively. The estimated population density equations also explained 63 and 64 percent of the variation in the small and large CRE models, respectively.

Growth in employment (GEMP) has positive and significant direct and indirect effect on growth in population (GPOP) in the large CRE investment model. The positive direct relationship implies that an increase in the number of jobs also increases population growth-people follow jobs. The positive indirect relationship also implies that growth in employment density of a neighboring country does have positive impact on population growth in a county. 
Table 5.3.1: SAR Results for Growth in Population Density Equation

\begin{tabular}{|c|c|c|c|c|c|c|c|c|}
\hline \multirow{2}{*}{$\begin{array}{l}\text { GPOP } \\
\text { Variables } \\
\end{array}$} & \multicolumn{4}{|l|}{ SCRE } & \multicolumn{4}{|l|}{ LCRE } \\
\hline & Coefficien & Direct & Indirect & Total & Coefficients & Direct & Indirect & Total \\
\hline GEMP & 0.033 & 0.034 & 0.005 & 0.039 & $0.394 * * *$ & $0.406^{* * *}$ & $0.058 * * *$ & $0.463 * * *$ \\
\hline GCRE & $0.398 * * *$ & $0.408 * * *$ & $0.059 * * *$ & $0.468 * * *$ & -0.044 & $-0.046 * *$ & $-0.007 * *$ & $-0.052 * *$ \\
\hline GPCI & $-0.384 * * *$ & $-0.395 * * *$ & $-0.057 * * *$ & $-0.452 * * *$ & $-0.384 * * *$ & $-0.395 * * *$ & $0.056 * * *$ & - \\
\hline EMPBASE & 0.013 & 0.013 & 0.002 & 0.015 & 0.012 & 0.012 & 0.002 & 0.014 \\
\hline POPBASE & $-0.029 * * *$ & $-0.030 * * *$ & $-0.004 * * *$ & $-0.034 * * *$ & $-0.029 * * *$ & $-0.029 * * *$ & $-0.004 * * *$ & - \\
\hline POVERTY & 0.001 & 0.001 & 0.000 & 0.001 & 0.000 & 0.001 & 0.000 & 0.001 \\
\hline PHP & $0.004 * *$ & $0.004 * *$ & $0.001 * *$ & $0.005^{* *}$ & $0.004 * *$ & $0.004 * *$ & $0.001 *$ & $0.005^{*}$ \\
\hline CMHV & $0.019 * * *$ & $0.020 * * *$ & $0.003^{* * *}$ & $0.023^{* * *}$ & $0.020 * * *$ & $0.020 * * *$ & $0.003^{* * *}$ & $0.023 * * *$ \\
\hline NONWTE & $0.001 * * *$ & $0.001 * * *$ & $0.000 * * *$ & $0.001 * * *$ & $0.001 * * *$ & $0.001 * * *$ & $0.000 * * *$ & $0.001 * * *$ \\
\hline CRIME & -0.002 & -0.002 & 0.000 & -0.002 & -0.001 & -0.001 & 0.000 & -0.002 \\
\hline METRO & -0.002 & -0.002 & 0.000 & -0.003 & -0.002 & -0.002 & 0.000 & -0.002 \\
\hline METROADJ & -0.007 & -0.007 & -0.001 & -0.008 & -0.007 & -0.007 & -0.001 & -0.008 \\
\hline $\mathrm{R}^{2}$ & 0.634 & & & & 0.635 & & & \\
\hline $\operatorname{sigma}^{\wedge} 2$ & 0.002 & & & & 0.002 & & & \\
\hline $\mathrm{N}$ & 299 & & & & 299 & & & \\
\hline
\end{tabular}

Growth in the density of small CRE investment has positive and significant direct and spillover effects on growth in population density. The direct effect is similar to the result of the 3SLS simultaneous equation; it implies that growth in SCRE investment increases the attractiveness of an area to live by increasing access to goods and services, and job opportunities. Even though the magnitude of the indirect effect is small, it suggests that increased number of small retail establishments in a neighboring county can have positive spillover effect on growth in population density in a county. This result may indicate a trend in commuter counties where people commute to a neighboring county that offers better opportunities.

Growth in the density of large CRE investment showed negative and significant direct and spillover effects on growth in population density. The direct effect is similar to the result of the 3SLS simultaneous equation; this unexpected negative relationship could mean that LCRE investments choose to locate more in suburbs with low population density areas because they 
require larger space/land; this can apply particularly to suburban shopping malls. Moreover, locating in low-population density areas may not restrict their market since they have an integrated supply scheme including online marketing to reach outside customers. The negative spillover effect of LCRE on population growth is too small to explain.

Growth in per capita income showed a positive spillover effect on population growth in the small CRE model and a negative spillover effect in large CRE model. However, the magnitudes of the coefficients are too small to explain.

Initial condition of population (POPBASE) has negative and significant direct and spillover effects in relationship with growth in population density. The direct effects are similar to the result of the 3SLS simultaneous equation. The negative direct relationship implies that counties that has initial higher numbers of population density in 2000 are growing slower compared to areas that has low initial population density. The indirect effects are again too small to explain.

New housing permits $(P H P)$ shows positive and significant relationship in both models. This indicates that increased new housing constructions explain the attractiveness of counties and play role in attracting residents, which leads to growth in population density $(G P O P)$. This positive direct effect is not significant in the 3SLS simultaneous equation model. New housing permits $(P H P)$ also showed a positive spillover effect on population density growth, implying that neighborhood housing constructions can also have positive effect on population density growth in a county.

A county's median house value $(C M H V)$ has a positive and significant direct relationship with population growth in both models. The direct effects are similar to the result of the 3SLS simultaneous equation model. The result can be argued to mean that median house value can represent amenities and opportunities in counties that potentially attract people to migrate in. The 
related demand for housing in those areas could be a reason for the higher housing prices. The spillover effects in both models are also positive and significant but, small magnitude.

The non-white population percentage (NONWTE) has positive and significant direct and indirect effect on population growth in both models. This non-white population percentage can represent not only people from different racial background but also the inflow of new immigrants in a county. An increased percentage of the non-white population can indicate the economic opportunity in a county that, in turn, leads to in migration and then growth in population. Higher birth rates among most non-white population may also be a contributing factor for the positive relationship. The result also indicates that diversity in neighboring counties also has positive spillover effect on population growth in a county; however, the magnitudes are too small to explain.

\subsubsection{Growth in Per CaPita Income Equation}

The result of Spatial Durbin Model (SDM) for the per capita income growth (GPCI) equations is presented in table 5.3.2. The first section of the table explains the small CRE investment model result, while the second section explains the large CRE investment model. The statistically significant value (0.177) and (0.183) of the spatial measure (Rho) indicate the existence of spatial interdependence among counties in both small and large CRE investment models, respectively. The overall fit $\left(\mathrm{R}^{2}\right)$ indicates 51 and 53 percent of the variation is explained in the small and large CRE investment models of per capita income growth equations, respectively.

Growth in employment (GEMP) has positive and significant direct and indirect effect on growth in per capita income (GPCI) in both models. The direct effect is similar to the result found in the 3SLS simultaneous model; implying, more jobs means more earning to a county. The spillover effects imply that growth in employment density (GEMP) of neighboring counties 
positively affects growth in per capita income of a county (GPCI). Growth in population (GPOP) has negative and significant direct effect on per capita income growth $(G P C I)$ in both models. The result of the direct effect is similar to that of the 3SLS simultaneous equation model. This observed negative relationship can be due to the fact that average county income is not keeping up with the growth pace in population. At the same time, it can imply a surplus of labor.

Initial condition of population density (POPBASE) has a direct positive and significant relationship with growth in per capita income in the large CRE model. This implies that counties that had large population in 2000 experienced a greater increase in per capita income compared to counties that had a small population. This confirms the theory that supports population growth as a stimulant for economic growth by providing the required consumer demand to generate favorable economies of scale in the production. Even though the magnitude is small, initial condition of population density showed negative and significant spillover effect, implying that neighboring population size can negatively affect the per capita income growth of a country. This could imply possible migration of people to a neighboring county leading to surplus of people.

The initial condition of per capita income (PCIBASE) has negative and significant direct relationship with growth in per capita income (GPCI) in both models. This implies a convergence of per capita income in the region. Poorer economies tend to grow faster than richer economies, suggesting a trend in regional growth towards development in rural areas (Deller et al. 2001) and supporting the income convergence argument. Initial per capita income condition has positive and significant spillover effect on per capita income growth $(G P C I)$ in the small CRE investment model, implying that the well-being of neighboring counties has a positive spillover effect on a county. 
TABLE 5.3.2: SDM RESULTS FOR GROWTH IN PER CAPITA INCOME EQUATION

\begin{tabular}{|c|c|c|c|c|c|c|c|c|}
\hline \multirow{2}{*}{$\frac{\text { GPCI }}{\text { Variable }}$} & \multicolumn{4}{|l|}{ SCRE } & \multicolumn{4}{|l|}{ LCRE } \\
\hline & Coefficien & Direct & Indirect & Total & Coefficient & Direct & Indirect & Total \\
\hline GEMP & $0.315^{* * *}$ & $0.332 * * *$ & $0.084 * * *$ & $0.416^{* * *}$ & $0.324 * * *$ & $0.336 * * *$ & $0.066 * *$ & $0.402^{*}$ \\
\hline GPOP & $-0.693 * * *$ & $-0.690 * * *$ & 0.012 & $-0.678 * * *$ & $-0.688 * * *$ & $-0.686 * * *$ & -0.012 & - \\
\hline GCRE & -0.025 & -0.039 & $-0.062 * * *$ & $-0.102 * * *$ & 0.036 & $0.049 * *$ & $0.059 * *$ & $0.109 *$ \\
\hline PCIBASE & $-0.077 * * *$ & $-0.068 * * *$ & $0.037^{* *}$ & -0.031 & $-0.111 * * *$ & $-0.113 * * *$ & -0.010 & - \\
\hline POPBASE & $0.010^{*}$ & 0.009 & $-0.007 * *$ & 0.002 & $0.052 * * *$ & $0.053^{* * *}$ & 0.006 & $0.059 *$ \\
\hline CREBASE & 0.000 & 0.000 & $0.000 * * *$ & $0.000 * *$ & $0.045^{* * *}$ & $0.048 * * *$ & 0.013 & $0.061^{*}$ \\
\hline NFIRM & -0.002 & -0.003 & -0.001 & -0.003 & 0.004 & 0.005 & 0.003 & 0.008 \\
\hline CMHV & $0.097^{* * *}$ & $0.090 * * *$ & $-0.031 * *$ & $0.060 * * *$ & $0.102 * * *$ & $0.102 * * *$ & 0.003 & $0.105^{*}$ \\
\hline PCITAX & -0.003 & -0.002 & $0.009 * * *$ & 0.007 & 0.002 & 0.004 & $0.007 * *$ & $0.012^{*}$ \\
\hline RETIRE & -0.001 & -0.001 & -0.001 & -0.002 & 0.000 & 0.000 & $0.000 * *$ & -0.000 \\
\hline METRO & -0.006 & -0.007 & -0.007 & -0.014 & -0.011 & $-0.015^{*}$ & -0.017 & - \\
\hline METROADJ & $0.014^{*}$ & 0.013* & -0.001 & 0.012 & $0.014^{*}$ & 0.012 & -0.006 & 0.006 \\
\hline W-GEMP & 0.027 & & & & 0.010 & & & \\
\hline W-GPOP & $0.139 * * *$ & & & & $0.107^{* *}$ & & & \\
\hline W-GCRE & $-0.057^{* *}$ & & & & $0.053^{* *}$ & & & \\
\hline W-PCIBASE & $0.052 * * *$ & & & & 0.009 & & & \\
\hline W-POPBASE & $-0.009 * * *$ & & & & -0.003 & & & \\
\hline W-CREBASE & $0.000 * * *$ & & & & 0.005 & & & \\
\hline W-NFIRM & -0.001 & & & & 0.002 & & & \\
\hline W-CMHV & $-0.049 * * *$ & & & & -0.014 & & & \\
\hline W-PCITAX & $0.010 * * *$ & & & & $0.007^{*}$ & & & \\
\hline W-RETIRE & -0.001 & & & & 0.000 & & & \\
\hline W-METRO & -0.006 & & & & $-0.015^{* *}$ & & & \\
\hline W-METROADJ & -0.004 & & & & -0.008 & & & \\
\hline $\mathrm{R}^{2}$ & 0.509 & & & & 0.526 & & & \\
\hline sigma^2 & 0.002 & & & & 0.002 & & & \\
\hline $\mathrm{N}$ & 299 & & & & 299 & & & \\
\hline
\end{tabular}

Growth in large CRE investment has positive direct and spillover effects on growth in per capita income growth $(G P C I)$. The direct effect is similar to the result found in the 3SLS simultaneous equation model; it implies that the investment is contributing to the earning and wellbeing of the economy. The positive spillover effect implies that the growth in large establishments in neighboring counties can have positive spillover effect on per capita income 
growth in a county. Initial condition of large CRE investment also showed positive and significant direct relationship with growth in per capita income.

Growth in small CRE showed insignificant direct relationship and negative spillover effect with growth in per capita income. The insignificant direct relationship is similar to the result found in the 3SLS simultaneous equation model. The insignificant relationship could be contributed by the strong positive relationship the investment has with growth in population density. The possibility that the investment has stronger effect on population growth than it has on income growth could lessen the positive effect the investment could have on per capita income growth. However, SCRE investment showed negative spillover effect on per capita income growth. Even though the magnitude of the spillover effect is small, it implies that growth in small retail establishments in neighboring counties can be a negative economic competitor for a county. It can imply a possible pulling effect of small establishments towards new investors and jobs from nearby counties.

County's median house value $(C M H V)$ has a positive and significant direct relationship with per capita income growth $(G P C I)$ in both models. CMHV can represent not only the quality of life and spending capacity of people living in a county but also the different opportunities. So having higher median housing value can relate to higher income population and/or higher job opportunities that lead to growth in per capita income $(G P C I)$. The direct effect is similar to that of the of 3SLS simultaneous equation. However, the result shows negative and significant spillover effect of neighboring median housing value to a county's per capita income growth; this could imply possible competition of neighboring counties in attracting business

Per capita income tax $(P C I T A X)$ has a positive and significant spillover effect on growth in per capita income (GPCI) in both models; however, the magnitudes of the coefficients are too 
small to explain. Dummy variable of the metro variable showed a negative relationship with per capita income in the large CRE model. Even though the magnitude of the coefficients are small, the negative relationship could be related to the effect of the great recession as most rural counties were less affected compared to their urban counterparts. 


\section{CHAPTER 6. SUMMARY AND CONCLUSION}

The main objective of this study is to examine the relationship between CRE investment and regional economic development among counties in the Northeast region of the United States. The objective is addressed by exploring the economic growth effects of CRE investments, particularly retail establishments and by analyzing how other regional socio-economic and growth factors, in turn, affect growth in retail establishments. The study included spatial as well as nonspatial model estimations. The assumed simultaneity of endogenous variables of growth in population density, employment density, per capita income, and density of retail establishments is accounted by the use of a three stage least squares (3SLS) simultaneous equation model in the nonspatial model.

The study area is composed of 299 counties of 12 states in Northeast region of the United States. The empirical model is analyzed using two different data sets to differentiate the possible different effects of relatively "small" and "large" retail establishments. This chapter is composed of three sections as follows. Section 6.1 presents the summary and conclusions of both the spatial and non-spatial estimation model results. Section 6.2 presents policy implications and recommendations, and finally, Section 6.3 presents limitations and future research related to the study.

\subsection{SUMMARY}

As explained above, the primary objective of this research is to explore the relationship between CRE investments, particularly retail establishments, and regional economic growth among counties in the Northeast region of the United States. The study concludes that indeed, growth in retail establishments plays a significant role in the economic growth process of the Northeast region of the United States. Although small retail establishments also contribute in the 
process of economic development, large retail establishments have a greater economic impact. Small retail establishments have a weak impact that is also statistically insignificant. This somewhat unexpected result is not inconsistent with casual observation and provides useful information for policy recommendations. Overall, the study provides information to policy makers on the economic role of both small and large retail establishments and socio-economic driving factors of the investment in the Northeast region of the U.S.

To estimate the models, a data set of socio-economic, accessibility, and fiscal variables of the Northeast region was collected for the period from 2000 to 2010. A system of four simultaneous equations using three stage least square (3SLS) method was empirically developed and estimated for the non-spatial model whereas, a spatial autoregressive models and spatial Durbin model based on contiguity weight matrix is used for the spatial model.

\subsubsection{Non-SPatial Model}

This section first summarizes the relationship between of growth in retail establishments and economic growth variables; growth in population density, employment density, and per capita income. Subsequently, the section summarizes the relationship between growth in retail establishments, and socio-economic and accessibility variables.

\section{Population density}

There is a positive and significant relationship between population density growth (GPOP) and small-scale commercial real estate (SCRE) investment. This can imply that growth in the density of SCRE investment increases the attractiveness of an area to live in by increasing access to goods and services and job opportunities. However, growth in the density of large commercial real estate $(L C R E)$ showed an unexpected negative relationship with growth in population density $(G P O P)$. This unexpected result, however, could mean that LCRE investors may choose to locate 
their investment in low-population density areas because their larger space/land requirement. However, locating in low-population density areas may not restrict their market outreach since they have integrated supply scheme including online marketing to reach outside market.

\section{Employment density}

Growth in the density of large CRE investment has the expected positive and significant relationship with growth in employment density. This signifies the positive economic role of the investment in stimulating and creating businesses and jobs. The initial level of large CRE investment has also showed positive and significant relationship with growth in employment (GEMP). This may imply that the initial condition of LCRE investment has a vital role in creating jobs and attracting other business to enhance employment growth and brings a long-term economic impact. However, growth in the density of SCRE investment and its initial condition showed a positive, but insignificant, relationship with growth in employment density. This result may be due to the fact that small businesses were the hardest hit during the great recession and lost greater shares of their employment compared to larger investments.

\section{Per capita income}

Growth in the density of large CRE investment showed a positive and significant relationship with growth in per capita income growth (GPCI), while growth in the density of small CRE investment has insignificant relationship. The positive relationship of LCRE implies that the investment is contributing to the earning and well-being of the economy. This result is also supported by the positive relationship of the investment with growth in employment density $(G E M P)$. The insignificant relationship observed with SCRE investment could be contributed by the insignificant relationship observed with growth in employment density (GEMP). Moreover, the strong positive relationship of SCRE investment with growth in population density may also 
lessen the positive effect the investment may have on growth in per capita income so long as the effect on population growth is higher than income growth.

The initial condition of LCRE investment showed a negative relationship with the growth in per capita income. This could be related to the negative relationship the initial condition of CRE investment showed with growth in CRE investment (GCRE).

\section{Socio-economic and accessibility variables}

The positive relationship of a county's median house value with both small and large CRE investments indicates that housing value is a positive driving factor for CRE investments. This positive relationship can be due to the potential role of housing value to provide exclusive insight to the future real estate market in an area and, hence, highly impact investment location decisions.

The fact that the number of firms in a county has a positive and significant effect only on small CRE investments rather than on large CRE investments indicates the important pulling effect of the agglomeration economy that arises from spatial proximity in attracting small CRE investment. On the other side, it also may imply that large CRE investments are less dependent on outside suppliers/firms because of their fully integrated marketing and distribution scheme. This also support the negative relationship observed between large retail establishments and population density.

The fiscal policy variables, such as per capita income tax and property tax, showed no significant effect on CRE investment, except the positive relationship that government expenditure showed on large CRE estate investments. The positive relationship could indicate that government expenditure can ultimately mean provision of expanded programs such as education, healthcare, highways, railroads, crime prevention etc. that, in turn, is expected to stimulate investment. Therefore, government expenditure can be an indirect pulling factor for large CRE investment. 
Fiscal variables such as tax reduction, interest rates, and government subsidies are mostly known to affect the commercial real estate market; however, these data were not available.

Accessibility variables such as road density and metro and metro adjacency are included in the model to represent the proximity to market demand and accessibility to supply. It was expected that this accessibly variable will show positive relationship with growth in retail establishments. However, no strong relationship was found.

\subsubsection{SPATIAL MODEL}

The main objective of the spatial model is to examine the relationship between CRE investments, specifically retail establishments, and regional economic growth among counties in the Northeast region of the United States by considering possible spatial dependencies in the data. The Lagrangian Multiplier (LM) test suggested the SAR model for the population density growth equation and SDM for per capita income equation. The employment density and CRE investment equations showed no spatial dependency. As explained in chapter 5, the spatial model estimated the small and large retail establishment data sets separately. The estimated coefficients indicate the direct effect on the county's marginal regional economic development and spatial spillover effect of neighboring county's marginal regional economic development. Even though the LM test supported the consideration of spatial analysis for the population and per capita equations, the coefficients of rho( $\rho$ ) that reflect the strength of the spatial dependency inherent in the data set are not as strong as expected. This caused the magnitude of most spillover coefficients to be small and difficult to explain. However, most of the direct effect results of the spatial model are consistent with the results of the 3SLS simultaneous equation model.

This section first summarizes the direct and indirect effects of growth in retail establishments, on population density growth and then, on per capita income growth. 


\section{Population density}

Growth in the density of small CRE investment showed a positive, significant, direct, and spillover effect on the growth in population density. The direct effect is similar to the result of the 3SLS simultaneous equation; it can imply that growth in the density of SCRE investment increases the attractiveness of an area to live in by increasing access to goods and services and job opportunities. Even though the magnitude of the indirect effect is small, it suggests that an increased number of small retail establishments of neighboring counties can have a positive spillover effect on growth in population density in a county. This result may indicate a trend in commuter counties, whereby people commute to neighboring counties for better opportunities. Growth in the density of large CRE investment showed negative and significant direct and spillover effects on the growth in population density. The direct effect is similar to the result of the 3SLS simultaneous equation; this unexpected negative relationship could mean that LCRE investments choose to locate more in low-population density areas because they require larger space/land; this can apply particularly to suburban shopping malls. Locating in low-population density areas may not restrict the market outreach of these large retail stores since they have a relatively better integrated supply scheme including online marketing. The negative spillover effect of LCRE on population growth is too small to explain.

\section{Per capita income}

Growth in large CRE investment has a positive direct and spillover effect on growth in per capita income $(G P C I)$. The direct effect is similar to the result found in the 3SLS simultaneous equation model; this implies that the investment is contributing to the earning and wellbeing of the economy. The indirect effect implies that growth in large retail establishments in neighboring counties have positive spillover effect in a county. Initial condition of large CRE investment also 
showed positive and significant direct relationship with growth in per capita income.

Growth in small CRE showed an insignificant direct relationship and a negative spillover effect with growth in per capita income. The insignificant direct relationship is similar to the result found in the 3SLS simultaneous equation model. This insignificant relationship could be contributed by the strong positive relationship the investment has with growth in population. The possibility that the investment has a stronger effect on population growth than it has on income growth could lessen the positive effect the investment could have on growth in per capita income. However, SCRE investment showed a negative spillover effect on per capita income growth. Even though the magnitude of the spillover effect is small, it indicates that growth in small retail establishments in neighboring counties can be a possible economic competitor for a county. It can imply a possible pulling effect of small establishments towards new investors and jobs from nearby counties. 


\subsection{Conclusions and Policy Recommendations}

Based on the empirical results of this study, some recommendations can be drawn to provide information to policy makers on the relationship between growth in retail establishments and economic development in the Northeast region of the United States.

$\checkmark$ The empirical analysis indicates that growth in retail establishments does indeed play a significant role in the economic growth process of the Northeast region of the United States from 2000 to 2010. Therefore, local governments should use retail developments as the focus of an economic development strategy. Incentives such as low interest rates in finance, lower tax rates, subsidies, and easy-and-fast procedures for construction permits can attract developers and business owners. Therefore, policy makers should identify and develop specific policies that encourage this particular investment in their area.

$\checkmark$ The empirical result shows a strong positive relationship between county median house values (CMHV) and growth in the density of establishments. This confirms the important role of CMHV in providing exclusive insight on the condition of the real estate market in an area and hence, highly impacts investment location decisions of CRE investors.

$>$ Therefore, local governments should try to come up with different strategies to maintain and improve neighborhood qualities in order to attract and get benefits from CRE investments. Some neighborhood revitalization policies can include, street lights, street cafes, landscaping, parking facilities, etc.

$\checkmark$ Government expenditure shows a positive relationship with growth in LCRE investments. Therefore, the provision of expanded programs such as education, health care, railroads, highways, crime prevention etc. can help to stimulate investment. 
Growth in population density shows a negative relationship with large CRE investments. This negative relationship could be due to the large space/land requirement of these investments that may be difficult to find in densely populated areas at a reasonable price. In this case, geographic isolation can give advantage to larger establishments given the fact that most of them also have the necessary supply and distribution scheme to reach outside customers. The boost in online retailing also created opportunities for retail stores located in low population density areas to pull a larger market presence from metropolitan areas. This statement is supported by Kim and Orazem's (2012) finding that broadband availability has a significant positive firm entry effect in rural areas.

$>$ This negative relationship found between growth in large retail establishments and population density calls local governments at densely populated areas to do extra efforts to attract this investors/business through different incentives mechanisms such as subsidy, tax breaks, financing etc. Moreover, local governments at low population density areas should understand the competitive advantage of their location to attract further investment in their area. 


\subsection{FUTURE RESEARCH}

There are several ways this study could be extended. The first limitation of this study pertains to data: retail establishments are used as one segment of the CRE investment. Even though retail establishments can give a general picture on the level of CRE investment in a county, it can be narrow as well as a broad representation of CRE investments. Retail establishments can be a broad category when considering the existence of different type of industries within retail store establishments. At the same time, it can be a narrow segment when considering other subdivisions within CRE investment such as office buildings, warehouses, wholesale establishments, etc. Therefore, to broaden the knowledge on the economic implications of the investment and to draw more practical policy implications, further studies should account not only the different sectors in the CRE investments but also for the different industries within the sectors.

Extension of the study by differentiating metro and non-metro counties is also one way to enrich the study in terms of understanding the distinct economic effects of CRE investment in these two different localities. Moreover, it will also help to identify specific core investment pulling factors specific to each sub-region 


\section{REFERENCES}

Alwitt, L., and Donley, T. (1997). Retail stores in poor urban neighborhoods. Journal of Consumer Affairs, 31(1), 139-164.

Ambrose, B.., and Lusht, K. (2008). Overview of the commercial real estate industry. National Association of Real Estate Investment Trusts (NAREIT) ®). https://www.reit.com/sites/default/files/portals/0/PDF/Overview\%20of\%20the\%20Com mercial\%20Real\%20Estate\%20Industry.pdf. Accessed, January 30, 2015.

Anselin, L. (1988). Spatial Econometrics: Methods and Models. Cambridge, MA: MIT Press.

Bashir, S., and Gebremedhin, T. (2012). Entrepreneurship and Regional Economic Development. Saarbrücken, Germany: Lambert Academic Publishing.

Brito, P., and Pereira, A. (2002). Housing and endogenous long-term growth. Journal of Urban Economics, 51(2), 246-271.

Boon, B. (2005). The availability and usefulness of real estate data in eastern Asia - a user's perspective. In Real Estate Indicators and Financial Stability, 91-111, BIS Papers No. 21 (April) Basel, Switzerland: Bank for International Settlements. http://www.bis.org/publ/bppdf/bispap21h.pdf. Accessed, December 11, 2014.

Bureau of Labor Statistics (2012). Employment outlook: 2010-2020. Monthly Labor Review, 135(1), 1-188. http://www.bls.gov/opub/mlr/2012/01/mlr201201.pdf. Accessed, January 27, 2015.

Carlino, A., and Mills, S. (1987). The Determinants of County Growth. Journal of Regional Science, 27(1), 39-54.

Chapple, K., and Jacobus, R. (2009). Retail trade as a route to neighborhood revitalization. In Urban and Regional Policy and Its Effect, 19-64, Washington, DC: Brookings Institution Press. 
Colavolpe, A. (2010). Demystifying the corporate real estate process: The retailer's perspective. Real Estate Issues, 35(1), 14 - 19.

Colwell, F., Gujral, S., and Coley, C. (1985). The impact of a shopping center on the value of surrounding properties. Real Estate Issues, 10(1), 35-39.

Coulson, E., and Kim, M. (2000). Residential investment, non-residential investment and GDP. American Real Estate and Urban Economics Association, 28(2), 233-247.

Thilmany, D., McKenney, N., Mushinski, D., and Weiler, S. (2005). Beggar-thy-neighbor economic development: A note on the effect of geographic interdependencies in rural retail markets. Annals of Regional Science, 39(3), 593-605.

Deller, C., Tsai, H., Marcouiller, W., and English, K. (2001). The role of amenities and quality of life in rural economic growth. American Journal of Agricultural Economics, 83(2), 352365.

Ding, C., and Knaap, G. (2002). Property value in inner city neighborhoods: the effect of home ownership, housing investment and economic development. Housing Policy Debate, 13(4), 701-727.

Ducatel, K., and Blomley, N. (1990). Rethinking retail capital. International Journal of Urban and Regional Research, 14(2), 207-227.

Fickes, M. (2007). Trends: Strategic thinking. Chain Store Age. http://www.chainstoreage.com/article/trends-strategic-thinking. Accessed, October 20, 2014.

Florence, A., Miller, N., Spivey, J., and Peng, R. (2010). Slicing, dicing and coping the size of the U.S. commercial real estate market. Commercial Real Estate Market, 16(2), 111-128.

Fujita, M., Krugman, P., and Mori, T. (1999). On the evolution of hierarchical urban systems. European Economic Review, 43(2), 209-251. 
Gebremariam, G., (2006). Modeling small business growth, migration behavior, local public services and median household income in Appalachia: a spatial simultaneous equations approach. Ph.D. Dissertation, West Virginia University, Morgantown, West Virginia.

Gibson, J., Albrecht, B., and Evans, B. (2003). Is retail trade a focus for real economic development in the knowledge-based economy? Applied Research in Economic Development, 1(1), 44-55.

Green, K. (1997). Follow the leader: How changes in residential and non-residential investment predict changes in GDP. Real Estate Economics, 25(2), 253-270.

Handerson, J., Kelly, T., and Taylor, B. (2000). The impact of agglomeration economies on estimated demand thresholds: an extension of Wensley and Stabler. Journal of Regional Science, 40(4), 719-733.

Hansen, N. (1967). Development pole theory in a regional context. Kyklos, International Review for Social Sciences, 20(4), 709-727.

Hongyu, L., Park, Y., and Siqi, Z. (2002).The interaction between housing investment and economic growth in China. International Real Estate Review, 5(1), 40 - 60.

Jackson, C. (2001). A model of spatial patterns across local retail property markets in Great Britain, Urban Studies, 38(9), 1445-1471.

Kahsai, S. (2009). An analysis of amenity-led rural economic development in northeast region: a spatial simultaneous equations approach. Ph.D. Dissertation, West Virginia University, Morgantown, West Virginia.

Kim, Y., and Orazem, P. (2012). Broadband internet and firm entry: evidence from rural Iowa. Working Paper No. 12026. Iowa State University, Department of Economics, Ames, Iowa. http://www.econ.iastate.edu/sites/default/files/publications/papers/p15696-201212-03.pdf. Accessed, February 32015.

Konish, H. (2005). Concentration of competing stores. Journal of Economics, 58(3), 488-512. 
Krugman, P. (1999). The role of geography in development. International Regional Science Review, 22(2), 142-161.

Krugman, P., and Venables, J. (1996). Integration, specialization and adjustment. European Economic Review, 40(3), 957-967.

LeSage, J., and Fischer, M. (2009). The impact of knowledge capital on regional total factor Productivity; working paper series. Social Science Research Network. http://papers.ssrn.com/sol3/papers.cfm?abstract id=1088301. Accessed, January 28, 2015.

Lieser, K., and Groh, A. (2011). The determinants of international commercial real estate investments. Journal of Real Estate Finance and Economics, 48(4), 611-659.

Ling, D., and Naranjo, A. (1997). Economic risk factors and commercial real estate returns. Journal of Real Estate Finance and Economics, 14(3), 283-307.

Lowe, M., and Crewe, L. (1991). Lollipop jobs for pin money? Retail employment explored. Royal Geographical Society, 23(4), 344-347.

Malizia, E. (1991). Forecasting demand for commercial real estate based on economic fundamentals of U.S. metro markets. Journal of Real Estate Research, 6(3), 251 - 265.

Miller, K., and Weber, B., (2014). Persistent poverty dynamics: understanding poverty trends over 50 years. Rural Policy Research Institute. Iowa City, Iowa.

Mojica, M. (2009). Examining the role of entrepreneurship in economic development in Appalachia. Ph.D. Dissertation. Morgantown, West Virginia, West Virginia University.

Mushinski, D., and Weiler, S. (2002). A note on the geographical interdependencies of retail market areas. Journal of Regional Science, 42(1), 75-86. 
Nair, R. (2011). How to invest in commercial real estate - guidelines for retail investors. http://www.joneslanglasalleblog.com/realestatecompass/real-estate/2011/06/how-toinvest-in-commercial-real-estate . Accessed, December 14, 2013.

National Association for Industrial and Office Parks (NAIOP). (2012). Commercial real estate development and construction rebounds in 2011. http://www.naiop.org/en/AboutNAIOP/News/NAIOP-News/2012/050112-Commercial-Real-Estate-Development-andConstruction-Rebounds-in-2011.aspx. Accessed, January 21, 2013.

Nondo, C. (2009). An empirical analysis of the interactions between environmental regulations and economic growth. Ph.D. Dissertation, West Virginia University, Morgantown, West Virginia.

Parr, J. (1973). Growth poles, regional development, and central place theory. Papers in Regional Science, 31(1), 173-212.

Perroux, F. (1950). Economic space: theory and application, Quarterly Journal of Economics, 64(1), 89-104.

Pittman, P., and Culp, P. (1995). When does retail count as economic development? Economic Development Review, 13(2), 4-6.

Porter, M. (1995) .The competitive advantage of the inner city. Harvard Business Review, 73(3), $55-71$.

Porter, M. (1997). New strategies for inner-city. Economic Development Quarterly, 11(1), 11-27.

Price, J., Kent, C., Springer, E., and Al, S. (2008). The economic impact of Tamarack. Center for Business and Economic Research, Marshall University, West Virginia. file://C:/Users/tezalex/Downloads/2008_12_31_Tamarack01072009.pdf. Accessed, February 4, 2015. 
Rajendra, K., Laurie, S., Roger, S., and Kenneth, B. (2002). A Kohonen self-organizing map approach to modeling growth pole dynamics. Networks and Spatial Economics, 2(2), 175-189.

Roback, J. (1982). Wages, rents, and the quality of life. Journal of Political Economy, 90(6), 12571278.

Romer, M. (1986). Increasing returns and long run growth. Journal of Political Economy, 94(5), 1002-1037.

Ruff, R. (2007).Commercial real estate: new paradigm old story. The Journal of Portfolio Management, 33(5), 27-36.

Seidman, K. (2006). Inner city commercial revitalization: A literature review. Cambridge, MA: MIT.

Solow, R. 1956. A contribution to the theory of economic growth. The Quarterly Journal of Economics, 70(1), 65-94.

Steinnes, N. (1982). Do people follow jobs or do jobs follow people? A causality in urban economics. Urban Studies, 19(2), 187 - 192.

Thilmany, D., McKenney, N., Mushinki, D., and Weiler, S. (2005). Beggar-thy-neighbor economic development: A note on the effect of geographic interdependencies in rural retail markets. Annals of Regional Science, 39(3), 593-605.

U.S. Census Bureau (2012). Statistical Abstract of the United States. http://www.census.gov/prod/2011pubs/12statab/domtrade.pdf . Accessed, January 28, 2015.

Vias, A. (2004). Bigger stores, more stores, or no stores: paths of retail restructuring in rural America. Journal of Rural Studies, 20(3), 303-318. 
West, D., and Orr, M. (2003). Downtown malls as engines of economic development, community spirit, and political capital. Economic Development Quarterly, 17(02), 193-204.

Wensely, M., and Stabler, J. (1998). Demand-threshold estimation for business activities in rural Saskatchewan. Journal of Regional Science, 38(1), 155-177.

Wincott, R., and Mueller, G. (1995). Market analysis in the appraisal process. Appraisal Journal, $63(1), 27-32$.

Williams, C. (1997). Rethinking the role of the retail sector in economic development. Service Industries Journal, 17(2), 205-220. 


\section{APPENDIX}

\begin{tabular}{|c|c|c|c|c|c|c|}
\hline $\begin{array}{l}\text { POP_SCRE } \\
\text { Im } \\
\text { probabilitv } \\
\text { Chi }\end{array}$ & $\begin{array}{l}\text { LAG } \\
\qquad \begin{array}{c}41 \\
0.000 \\
6.64\end{array}\end{array}$ & $\begin{array}{l}\text { SEM } \\
32.35 \\
0.000 \\
6.64\end{array}$ & $\begin{array}{c}\text { ROBUSTLAG } \\
10.7 \\
0.001 \\
6.64\end{array}$ & $\begin{array}{c}\text { ROBUSTSEM } \\
2.05 \\
0.153 \\
6.64\end{array}$ & $\begin{array}{l}\text { SDM } \\
\text { LR spatial lag } \\
\text { prob spatial lag }\end{array}$ & $\begin{array}{l}12.759 \\
0.3868\end{array}$ \\
\hline $\begin{array}{l}\text { POP LCRE } \\
\text { Im } \\
\text { probability } \\
\text { Chi }\end{array}$ & $\begin{array}{l}\text { LAG } \\
40.8 \\
0.000 \\
6.64\end{array}$ & $\begin{array}{c}\text { SEM } \\
33.1 \\
0.000 \\
6.64\end{array}$ & $\begin{array}{c}\text { ROBUSTLAG } \\
10.1 \\
0.0015 \\
6.64\end{array}$ & $\begin{array}{c}\text { ROBUSTSEM } \\
2.41 \\
0.1206 \\
6.640\end{array}$ & $\begin{array}{c}\text { SDM } \\
\text { LR spatial lag } \\
\text { prob spatial lag }\end{array}$ & $\begin{array}{l}12.295 \\
0.4223\end{array}$ \\
\hline $\begin{array}{l}\text { EMP SCRE } \\
\text { Im } \\
\text { probability } \\
\text { Chi }\end{array}$ & $\begin{array}{l}\text { LAG } \\
0.34 \\
0.56 \\
6.64\end{array}$ & $\begin{array}{l}\text { SEM } \\
5.96 \\
0.01 \\
6.64\end{array}$ & ROBUSTLAG & ROBUSTSEM & SDM & \\
\hline $\begin{array}{l}\text { EMP_LCRE } \\
\text { Im } \\
\text { probabilitv } \\
\text { Chi }\end{array}$ & $\begin{array}{l}\text { LAG } \\
0.489 \\
0.48 \\
6.64\end{array}$ & $\begin{array}{c}\text { SEM } \\
6.18 \\
0.013 \\
6.64\end{array}$ & ROBUSTLAG & ROBUSTSEM & SDM & \\
\hline $\begin{array}{l}\text { PCI SCRE } \\
\text { Im } \\
\text { probability } \\
\text { Chi }\end{array}$ & $\begin{array}{l}\text { LAG } \\
41.58 \\
0.000 \\
6.64\end{array}$ & $\begin{array}{l}\text { SEM } \\
53.35 \\
0.000 \\
6.64\end{array}$ & $\begin{array}{c}\text { ROBUSTLAG } \\
3.86 \\
0.049 \\
6.64\end{array}$ & $\begin{array}{c}\text { ROBUSTSEM } \\
68.30 \\
0.000 \\
6.64\end{array}$ & $\begin{array}{c}\text { SDM } \\
\text { LR spatial error } \\
\text { prob spatial error }\end{array}$ & $\begin{array}{c}43.164 \\
2.12 E-05\end{array}$ \\
\hline $\begin{array}{l}\text { PCI LCRE } \\
\text { Im } \\
\text { probability } \\
\text { Chi }\end{array}$ & $\begin{array}{l}\text { LAG } \\
34.98 \\
0.000 \\
6.64\end{array}$ & $\begin{array}{c}\text { SEM } \\
43.82 \\
0.000 \\
6.64\end{array}$ & $\begin{array}{c}\text { ROBUSTLAG } \\
4.13 \\
0.042 \\
6.64\end{array}$ & $\begin{array}{c}\text { ROBUSTSEM } \\
53.18 \\
0.00 \\
6.64\end{array}$ & $\begin{array}{c}\text { SDM } \\
\text { LR spatial error } \\
\text { prob spatial error }\end{array}$ & $\begin{array}{c}37.17 \\
2.09 E-04\end{array}$ \\
\hline $\begin{array}{l}\text { SCRE } \\
\text { Im } \\
\text { probabilitv } \\
\text { Chi } \\
\text { LCRE }\end{array}$ & $\begin{array}{c}\text { LAG } \\
4.99 \\
0.026 \\
6.64\end{array}$ & $\begin{array}{c}\text { SEM } \\
4.90 \\
0.028 \\
6.64\end{array}$ & ROBUSTLAG & ROBUSTSEM & SDM & \\
\hline $\begin{array}{l}\text { Im } \\
\text { probability }\end{array}$ & $\begin{array}{c}\text { LAG } \\
5.55 \\
0.018\end{array}$ & $\begin{array}{c}\text { SEM } \\
4.56 \\
0.018\end{array}$ & ROBUSTLAG & ROBUSTSEM & SDM & \\
\hline Chi & 6.64 & 6.64 & & & & \\
\hline
\end{tabular}

